\title{
Water vapour transport in the tropical tropopause region in coupled Chemistry-Climate Models and ERA-40 reanalysis data
}

\author{
Stefanie Kremser ${ }^{1,2}$, Ingo Wohltmann ${ }^{1}$, Markus Rex ${ }^{1}$, Ulrike Langematz ${ }^{2}$, Martin Dameris ${ }^{3}$, and Markus Kunze ${ }^{2}$ \\ ${ }^{1}$ Stiftung Alfred-Wegener Institute for Polar and Marine Research, Potsdam, Germany \\ ${ }^{2}$ Institut für Meteorologie, Freie Universität Berlin, Berlin, Germany \\ ${ }^{3}$ Deutsches Zentrum für Luft- und Raumfahrt, Institut für Physik der Atmosphäre, Oberpfaffenhofen, Germany
}

Received: 1 February 2008 - Published in Atmos. Chem. Phys. Discuss.: 9 June 2008

Revised: 7 April 2009 - Accepted: 7 April 2009 - Published: 23 April 2009

\begin{abstract}
In this study backward trajectories from the tropical lower stratosphere were calculated for the Northern Hemisphere (NH) winters 1995-1996, 1997-1998 (El Niño) and 1998-1999 (La Niña) and summers 1996, 1997 and 1999 using both ERA-40 reanalysis data of the European Centre for Medium-Range Weather Forecast (ECMWF) and coupled Chemistry-Climate Model (CCM) data. The calculated trajectories were analysed to determine the distribution of points where individual air masses encounter the minimum temperature and thus minimum water vapour mixing ratio during their ascent through the tropical tropopause layer (TTL) into the stratosphere. The geographical distribution of these dehydration points and the local conditions there determine the overall water vapour entry into the stratosphere. Results of two CCMs are presented: the ECHAM4.L39(DLR)/CHEM (hereafter: E39/C) from the German Aerospace Center (DLR) and the Freie Universität Berlin Climate Middle Atmosphere Model with interactive chemistry (hereafter: FUB-CMAM-CHEM). In the FUBCMAM-CHEM model the minimum temperatures are overestimated by about $9 \mathrm{~K}$ in $\mathrm{NH}$ winter and about $3 \mathrm{~K}$ in $\mathrm{NH}$ summer, resulting in too high water vapour entry values compared to ERA-40. However, the geographical distribution of dehydration points is fairly similar to ERA-40 for NH winter 1995-1996 and 1998-1999. The distribution of dehydration points in the boreal summer 1996 suggests an influence of the Indian monsoon upon the water vapour transport. The E39/C model displays a temperature bias of about $+5 \mathrm{~K}$. Hence, the minimum water vapour mixing ratios are higher relative to ERA-40. The geographical distribution of dehydration points
\end{abstract}

Correspondence to: $\mathrm{M}$. Rex (markus.rex@awi.de) is fairly well in NH winter 1995-1996 and 1997-1998 with respect to ERA-40. The distribution is not reproduced for the NH winter 1998-1999 (La Niña event) compared to ERA40. There is an excessive water vapour flux through warm regions e.g. Africa in the $\mathrm{NH}$ winter and summer. The possible influence of the Indian monsoon on the transport is not seen in the boreal summer 1996. Further, the residence times of air parcels in the TTL were derived from the trajectory calculations. The analysis of the residence times reveals that in both CCMs residence times in the TTL are lower compared to ERA-40 and the seasonal variation is hardly present.

\section{Introduction}

Water vapour is the most important greenhouse gas (GHG) in the atmosphere. In contrast to tropospheric warming, water vapour leads to a radiative cooling in the stratosphere (Forster and Shine, 1999). An increase in stratospheric water vapour also changes the stratospheric ozone distribution by changing radical driven ozone loss cycles in the lower stratosphere and increasing polar ozone loss by enhancing the effectiveness of the heterogeneous reactions that destroy ozone there (Oltmans and Hofmann, 1995).

Water vapour in the stratosphere results from two processes. About one third or less (depending on altitude and latitude) comes from the oxidation of methane. But the majority of stratospheric water vapour comes from the direct flux of water vapour from the troposphere into the stratosphere through the tropical tropopause layer (TTL) (c.f. Sect. 1.1). The humid tropospheric air is freeze dried when moving through the cold tropical tropopause (e.g. Brewer, 1949), a process that is very sensitive to temperature and

Published by Copernicus Publications on behalf of the European Geosciences Union. 
the interaction between horizontal and vertical transport of air in the TTL. Hence, small changes in the thermal structure or the dynamical properties of this region of the atmosphere can have a large impact on stratospheric water vapour fields and therefore significantly couple to the ozone layer and global climate. In Chemistry-Climate Models (CCMs) a correct representation of the processes that determine the flux of water vapour through the TTL is essential for projections of the impact of these coupling mechanisms in a changing climate.

In this study a Lagrangian trajectory module is used to diagnose the representation of water vapour transport through the TTL in two CCMs and to compare it to similar calculations that are designed to give the closest representation of these processes to the real atmosphere that can be achieved.

\subsection{Processes in the TTL}

Brewer (1949) suggested that air enters the stratosphere primarily in the tropics, because only there the temperatures are cold enough to dehydrate the moist tropospheric air to the observed stratospheric values. Air then moves up and poleward before descending back into the troposphere. This concept of the Brewer-Dobson Circulation (BDC) was confirmed by several studies (e.g., Holton et al., 1995). In the tropics the transition region from the humid, turbulent troposphere to the dry, stable stratosphere is called the Tropical Tropopause Layer (TTL). There are multiple definitions of the TTL. Following Highwood and Hoskins (1998), the TTL extends from the main convective outflow $(\sim 14 \mathrm{~km})$ to the cold point of the tropopause (CPT) at an altitude of about $17 \mathrm{~km}$. Air is basically tropospheric below this level and stratospheric above this level. Thus this region is vital in studying water vapour transport into the stratosphere. In the lower part of the TTL convection dominates the vertical transport and in the upper part radiative processes determine the vertical transport (Gettelman et al., 2004). This is illustrated schematically in Fig. 1 (top panel). Past investigations show that overshooting convection into the interior of the TTL is not a common occurrence, suggesting that most air masses ascend through the coldest region in slow radiatively driven diabatic motion (Gettelman et al., 2004). Using backward trajectory calculations extending back from a stratospheric level (Fig. 1, top panel) to examine the transport processes in the TTL has the advantage that one can focus on the transport through the cold point into the stratosphere without being affected by tropospheric processes (e.g., convection). The individual cold point for each trajectory coincides with the temperature minimum along the trajectory and is termed the final dehydration point. Microphysical processes and sedimentation of ice particles reduce the water vapour in the air mass to a minimum in this point and after this point the water vapour content in the air mass has no memory to the air mass history before, with the exception of a speculative contribution of particulate water entry into the stratosphere (e.g., Sherwood and Dessler,
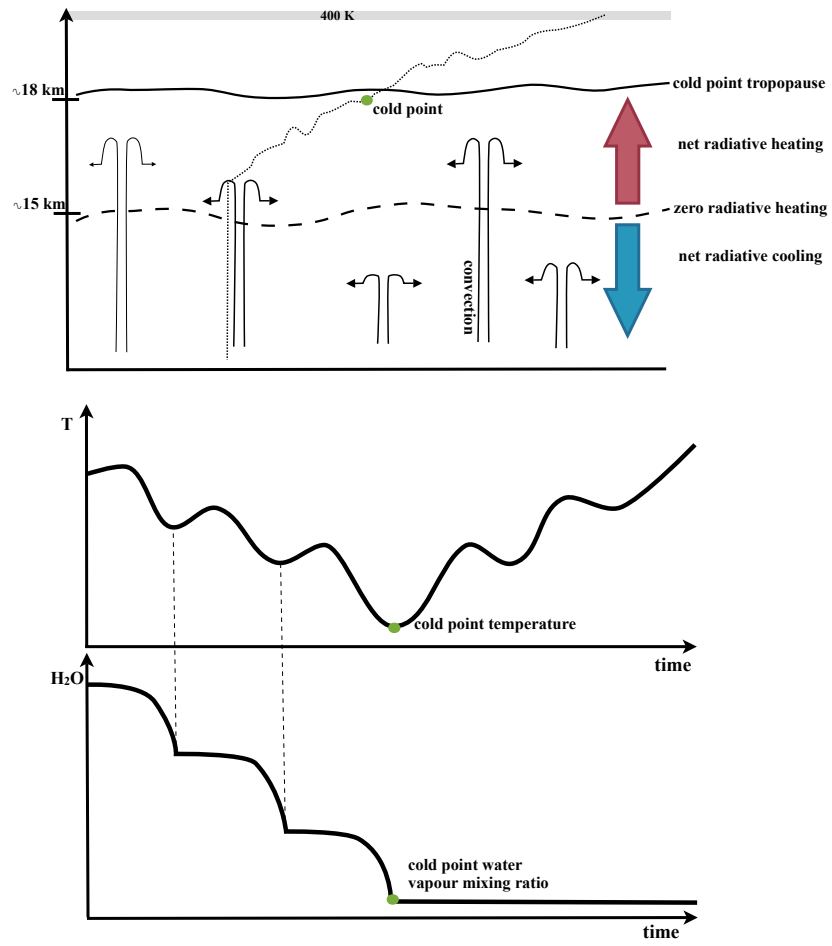

Fig. 1. Schematic picture that illustrates the Lagrangian cold point concept. The Lagrangian cold point (green dot in the top panel) corresponds to the lowest temperature along an individual air mass trajectory and thus to the lowest water vapour value. It is located close to the cold point tropopause but due to the interaction between horizontal and vertical transport it does not exactly coincide with it. This figure shows the time series of temperature (middle) and water vapour (bottom) experienced along a trajectory. In addition, it demonstrates that, if one calculates backward trajectories (represented by the dotted curve in the top panel) the water vapour content of an air parcel will not be affected by processes before the cold point.

2000; Notholt et al., 2005) which would depend on aerosol density - this process is not considered here. Hence, only the conditions in the dehydration point determine the direct entry of water vapour into the stratosphere (Fig. 1).

\subsection{Past investigations of trajectory calculations}

First, Gettelman et al. (2002) used 10-day backward trajectories to explore the relationship between the observed variation of temperature and water vapour in the TTL. Bonazzola and Haynes (2004) have also calculated trajectories based on ECMWF operational data to determine patterns of transport and encountered temperatures, showing that both effects must be taken into account for understanding variability and changes of stratospheric water vapour. In addition, they examined interannual variability and found that air masses are dehydrated more efficiently in cold La Niña relative to 
warmer El Niño years. Also using ECMWF backward trajectories Fueglistaler et al. (2004) then demonstrated that estimates of water vapour mixing ratios of air entering the stratosphere were in good agreement with satellite observations. The analysis by Fueglistaler et al. (2004) highlighted the importance of particular geographical areas for tropical troposphere to stratosphere transport (TST), finding that the Western Pacific is the dominant contributor to stratospheric air. In a subsequent study, Fueglistaler et al. (2005) presented backward trajectory calculations in the tropics based on ECMWF ERA-40 data between 1979 and 2001 determining that stratospheric water vapour mixing ratios are in good agreement with various balloon and satellite measurements. The study by Hatsushika and Yamazaki (2003) used trajectory calculations based on atmospheric general circulation model data (AGCM) to investigate the entry process of air parcels from the tropical troposphere to the stratosphere and to examine the dehydration process during their ascent through the TTL. Krüger et al. (2008) calculated trajectories based on diabatic heating/cooling rates to present a long term climatology of transport processes in the upper part of the TTL.

\subsection{Vertical transport}

In CCMs species transport is implemented by using an advection scheme that is driven by the three dimensional wind field. Uncertainties in the modeled water vapour entry into the stratosphere come from uncertainties in the temperature fields, uncertainties in the wind fields and numerical properties of the advection scheme, like numerical diffusion. The tropopause is a region of extremely steep vertical gradients in water vapour mixing ratios and vertical diffusion from the numerical properties of the advection scheme can obscure problems with the more physically based dynamical properties like temperature or wind fields. To isolate the dynamical properties of the model from the effect of numerical diffusion the Lagrangian trajectory module driven by the wind and temperature fields of the CCMs is used to advect water vapour through the TTL. Since the advection schemes in the CCMs are driven by the three dimensional wind fields including the vertical winds, the trajectory calculations that are used to diagnose transport in the CCMs are also driven by the vertical winds.

To evaluate the representation of the water vapour transport in CCMs, the calculations mentioned above are compared with similar calculations that are designed to reflect the processes in the real atmosphere as close as possible. These calculations are driven by meteorological reanalysis data from ECMWF (ERA-40) (Uppala et al., 2005). ERA40 reanalysis data are currently the best available long-term dataset for the purpose of this study even though past investigations show that ERA-40 reanalysis data display uncertainties in the temperature and wind field compared to observations (e.g., Christensen et al., 2007). But these are strongest in the stratosphere of the polar regions (Parrondo et al., 2007) and relatively small in the tropical tropopause region (e.g., Christensen et al., 2007).

Vertical winds from analysis data often suffer from excessive noise and errors in their mean magnitude, which results in vertical diffusion many orders of magnitude larger than observed and overall unrealistic vertical transport. Wohltmann and Rex (2008) showed that trajectory calculations using calculated diabatic heating rates to drive vertical transport are much more realistic. These are termed diabatic trajectories in contrast to trajectories that are driven by vertical winds, which are termed kinematic trajectories. These results are in line with the earlier work by Schoeberl et al. (2003) who also concluded that diabatic trajectories are closest to reality. Hence the calculations based on ERA-40 data that are designed to reflect the real atmosphere are driven by diabatic heating rates.

\subsection{Residence time}

Besides examining the water vapour transport, the residence time of the air parcels in the upper part of the TTL was determined. The residence time is equivalent to the time that each air parcel resides in the TTL. This is an important parameter/measurement for short-lived chemical compounds which can reach the stratosphere and thus can have a major impact on stratospheric chemistry (such as very short-lived bromine species WMO, 2007). The residence time allows to assess which compounds can reach the stratosphere chemically unaltered and which species will be chemically processed before reaching the stratosphere (Holton et al., 1995). Due to the weaker BDC in $\mathrm{NH}$ summer than in $\mathrm{NH}$ winter (Bonazzola and Haynes, 2004), it is expected that in NH summer the residence times of the parcels are longer than in $\mathrm{NH}$ winter.

In the lower TTL tropospheric processes (e.g., convection) dominate, which decline rapidly with height (Gettelman et al., 2004). Convection still contributes significantly to the vertical transport in the lower part of the TTL (Ren et al., 2007) and therefore the diabatic trajectories used here, which do not include latent heat release, give inaccurate results. In the upper part of the TTL the radiative balance of the TTL determines the strength and direction of the vertical motion (Gettelman et al., 2004) and therefore convective transport is less likely to be important for the vertical transport.

The purpose of this study is twofold: First, we want to test the ability of global CCMs to realistically capture the transport of water vapour from the troposphere into the stratosphere. Current CCMs differ in many aspects, such as the number and accuracy of implemented dynamical, physical and chemical processes, the degree of coupling of these processes, or the horizontal and vertical resolution and vertical domain. In a first attempt to validate CCM simulations, the Chemistry-Climate Model Validation (CCMVal) activity, that is part of the World Climate Research Programme (WCRP) Stratospheric Processes and their Role in Climate (SPARC) initiative, revealed large discrepancies of lower 
stratospheric water vapour concentrations in transient CCM simulations of the recent past (Eyring et al., 2006). In our study we want to extend this inter-comparison by focusing on specific aspects of the water vapour transport through the TTL in a subset of two CCMs, i.e. the geographical distribution, the residence time of water vapour in the TTL, and interannual variability of the transport.

Second we want to introduce a diagnostic method that allows us to assess and compare the transport characteristics in the TTL of different CCMs. This method, the determination of water vapour transport into the stratosphere using Lagrangian backward trajectories, has been established successfully to derive water vapour transport from observations and is applied here for the first time to wind and temperature fields from CCMs. We compare the transport characteristics of water vapour through the TTL in the two CCMs with the water vapour transport in the real atmosphere derived from similar calculations based on ERA-40 reanalysis. It should be noted that we do not validate modeled water vapour distributions with those from ERA-40 or other observational data sets, but want to assess here the transport through the tropical TTL that leads to the observed or modeled water vapour concentrations in the lower stratosphere. We therefore use only dynamical, thermal and radiative quantities from ERA40 to drive the trajectory calculations for the assessment of the transport representation in the models.

This paper is organized as follows; in Sect. 2 the data and method used for the trajectory calculations are described. The results are presented and discussed in Sect. 3, and are summarized in Sect. 4. Conclusion and a brief outlook are provided in Sect. 5.

\section{Data and method}

\subsection{ERA-40 reanalysis data and model data}

The ERA-40 dataset, available every 6 hours, covers the period from 1957 to August 2002. The data were produced from the ECMWF in collaboration with many institutions. We have extracted the data on a $2^{\circ} \times 2^{\circ}$ latitude-longitude grid. In the vertical a hybrid $\sigma-p$ coordinate system with 60 levels is used (for a detailed description see Uppala et al., 2005).

Model data were provided from two CCMs:

- E39/C: The E39/C model is operated at the German Aerospace Center (DLR). The E39/C model has a spectral horizontal resolution of T30, which is a resolution of $3.75^{\circ} \times 3.75^{\circ}$ in the corresponding Gaussian grid on which the models physics, chemistry, and tracer transport are calculated. The E39/C model has a hybrid $\sigma-p$ coordinate system. In the vertical the model has 39 layers and the top of the model is centered at 10 $\mathrm{hPa}(\sim 30 \mathrm{~km})$. The vertical resolution in the tropical tropopause region is approximately $600 \mathrm{~m}$. The transient simulation of the E39/C model covers the 40 year period between 1960 and 1999. Based on observations, several boundary conditions are prescribed (e.g., sea surface temperature (SST), greenhouse gas and halogen concentrations). The E39/C model is described in detail by Dameris et al. (2005).

- FUB-CMAM-CHEM: The model is based on the Freie Universität Berlin Climate Middle Atmosphere Model, described in detail by Pawson et al. (1998). It has been updated and coupled to an interactive chemistry module as described in Langematz et al. (2005). The FUB-CMAM-CHEM has been run at T21 horizontal resolution, corresponding to $5.6^{\circ} \times 5.6^{\circ}$ in a Gaussian longitude-latitude grid. In the vertical a hybrid $\sigma-p$ coordinate system is used with 34 levels from the surface up to the top at $84 \mathrm{~km}$. The vertical distance between two layers is $2 \mathrm{~km}$ in the tropopause region and $3.5 \mathrm{~km}$ in the middle atmosphere. The simulation covers the period from 1980 to 1999 and was run with transient boundary conditions for SSTs, GHGs and halogens.

Both CCMs are based on the same dynamical model, the ECHAM general circulation model, developed at MaxPlanck-Institut for Meteorology. The models differ in their horizontal and vertical resolutions of the analysed integrations, the vertical domain, as well as in details of the physical parameterizations. While FUB-CMAM-CHEM provides a better representation of the physics and dynamics of the upper stratosphere and mesosphere which is important for representing tropical transport by the $\mathrm{BDC}, \mathrm{E} 39 / \mathrm{C}$ provides the better vertical representation at the tropical tropopause and includes updated parameterizations of tropical deep convection compared to the FUB-model.

\subsection{Trajectory models}

Two types of trajectories are calculated: kinematic and diabatic trajectories. In the "kinematic method" air parcels are transported horizontally on pressure surfaces and the vertical motion across these surfaces is generated by the vertical wind. Since the water vapour transport by advection schemes in the CCMs is driven by vertical winds, kinematic trajectories were calculated with CCM data. The vertical wind is calculated from the continuity equation. Since horizontal winds are many orders of magnitude larger than the vertical wind, small errors in the horizontal wind field can lead to large errors in the vertical wind (Wohltmann and Rex, 2008).

In the second approach, the "diabatic method", the propagation of horizontal wind errors into the vertical is avoided. In stable stratified regions like the stratosphere one can use the potential temperature $(\Theta)$ as vertical coordinate instead of the pressure. Thus, the horizontal transport takes place on isentropic surfaces and radiative heating rates are applied 
as vertical velocity. With the reanalysis data ERA-40 both approaches were used. But with the exception for the residence time calculation in Figures 14 and 15, the results from the kinematic calculations are very similar with just slightly more zonal distribution of dehydration points (c.f. Wohltmann and Rex, 2008). For the residence time both approaches result in very different distributions and results from both calculations are presented.

\subsection{Simulations}

Backward trajectories initialized in the stratosphere are calculated. For these calculations it is important that the end points lie above the cold point tropopause and only those trajectories are used, that run back well into the troposphere. In both CCMs the potential temperature of the cold point is higher compared to ERA-40. Also the temperature minimum is less sharp and the cold region is broader. Hence, the calculations based on CCM data need to end higher up in potential temperature space and they need to cover a broader vertical region. Thus the trajectories based on CCM data are started on the $470 \mathrm{~K}$ surface and those based on ERA-40 data are initialized at $\Theta=400 \mathrm{~K}$. In both cases only trajectories are used for the analysis that reached the $365 \mathrm{~K}$ level (details below). This choice of the vertical region makes sure that the cold point lies within the vertical region covered by the calculations.

The trajectories are started between $30^{\circ} \mathrm{N}$ and $30^{\circ} \mathrm{S}$ for all longitudes on a $2^{\circ} \times 2^{\circ}$ grid (5611 trajectories per run). This setup is similar to the studies of Bonazzola and Haynes (2004) and Krüger et al. (2008). The trajectories based on ERA-40 data are calculated back for 89 days. Since the trajectories based on CCM data needed to cover a broader vertical range they are calculated back for 178 days. Analysis of the seasonal distribution of the cold points shows, that the probability density function (PDF) of the day of the year when the cold point is reached is very comparable for the ERA-40 analysis and the CCM analysis. The integration time step was $10 \mathrm{~min}$ and the position (longitude, latitude), pressure $(p)$, temperature $(T)$ and potential temperature are stored every $2 \mathrm{~h}$. The temperature minimum along the trajectory path was calculated, the potential temperature and the location where it occurs are stored.

For the trajectory analysis only trajectories that stayed at least 2 days below $\Theta=365 \mathrm{~K}$ (upper troposphere) are considered. This set of trajectories is referred to as the "troposphere-to-stratosphere" (TS) trajectories (using the terminology of Bonazzola and Haynes, 2004). Trajectories that do not reach the troposphere, and do not contribute to the troposphere to stratosphere transport, are not analysed. The number of TS trajectories should be lower in NH summer than in NH winter, due to the weaker BDC in NH summer than in NH winter (Bonazzola and Haynes, 2004). For the ERA-40 reanalysis data the lowest percentages of TS diabatic trajectories are obtained in the $\mathrm{NH}$ summer whereas for the FUB model the number of TS trajectories is lowest in $\mathrm{NH}$ winter.

The humidity of air that enters the stratosphere is given by the minimum water vapour mixing ratio $\left(\chi_{\mathrm{H}_{2} \mathrm{O}_{-} \min }\right)$ assumed along the trajectory during its ascent. Here $\chi_{\mathrm{H}_{2} \mathrm{O} \_ \text {min }}$ is estimated from saturation vapour pressure over ice at the temperature minimum.

$\chi_{\mathrm{H}_{2} \mathrm{O} \_ \text {min }}=\frac{p_{s}}{p_{\text {cold_point }}}$

where $p_{s}$ is the saturation pressure of water vapour and $p_{\text {cold_point }}$ is the ambient pressure. The saturation pressure was calculated by the equation given in Marti and Mauersberger (1993) which allows the calculation of the water vapour pressure between $170 \mathrm{~K}$ and the triple point of water, with an accuracy of about 2\% (Marti and Mauersberger, 1993):

$p_{s}=10^{\frac{-2663.5}{T}+12.537}$

in which $p$ is in $\mathrm{hPa}$ and $T$ in $\mathrm{K}$. This approach neglects supersaturation and non-equilibrium processes. These can enhance the water vapour entry into the stratosphere slightly but predominantly in the form of a relatively flat scaling factor. Since we are comparing the results from the simulations that are driven by CCM data with calculations that are based on the same assumptions, a flat scaling of the water vapour shown in all figures does not have an impact on the conclusions.

In addition, the residence times of air parcels in the TTL are derived from the trajectory calculations. The results for the upper TTL (layer from $\Theta=385-395 \mathrm{~K}$ ) are shown. For the computation of the residence time the number of time steps for which a trajectory was located in the corresponding layer was counted. By multiplying by the time step length (10 $\mathrm{min})$, the residence time of a trajectory in the corresponding layer was determined.

Trajectories for the NH winters 1995-1996, 1997-1998 and 1998-1999 (started on 28 February) and for the NH summer 1996 (started on 30 August) are calculated. These years are chosen because they allow the comparison of transport processes between winter and summer, and for $\mathrm{NH}$ winters the comparison of different phases of the El Niño Southern Oscillation (ENSO). ENSO changes the temperatures and the circulation of the tropical tropopause region and the convective activity in the tropics (e.g., Gettelman et al., 2001). NH winter 1997-1998 corresponds to El Niño conditions, while the NH winter 1998-1999 corresponds to La Niña conditions. In NH winter 1995-1996 ENSO was in a neutral phase. 


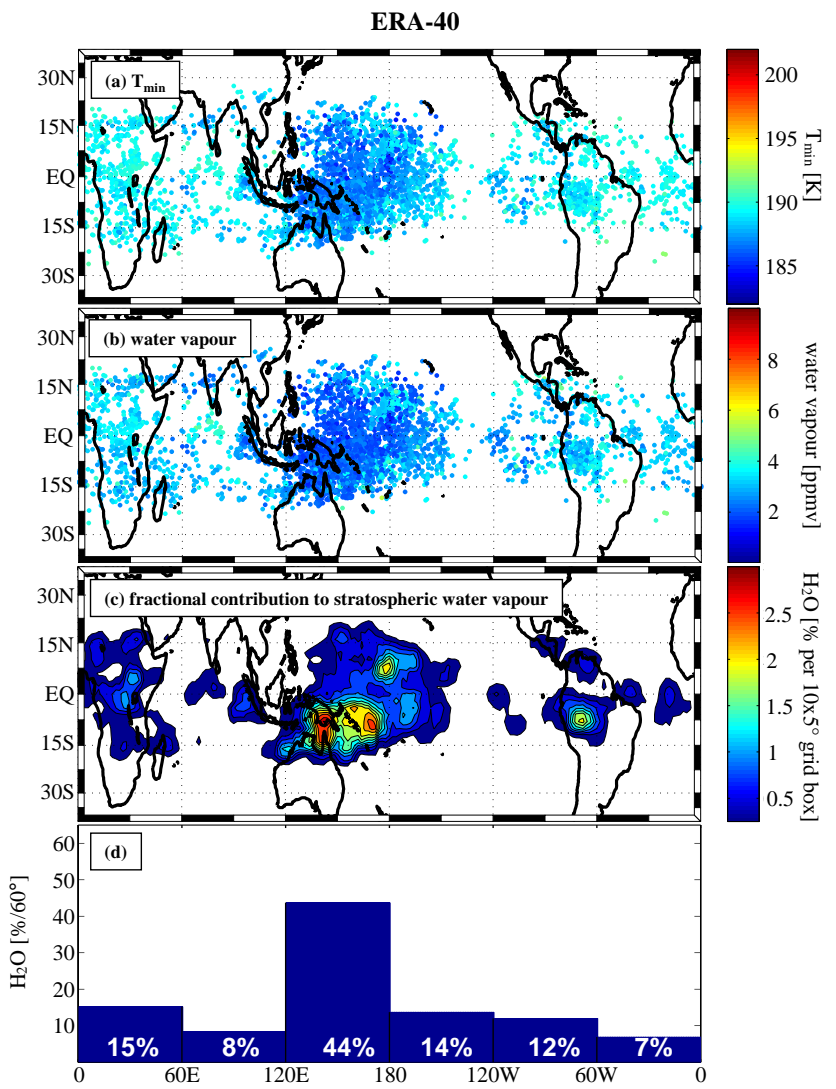

Fig. 2. NH winter 1995-1996. The scatter plots (panel a and b) show the geographical distribution of the dehydration points for ERA-40. Color code in (a) shows the minimum temperatures experienced by the TS trajectories and in (b) the corresponding equilibrium water vapour mixing ratios. Panel (c) illustrates the fractional contribution to stratospheric water vapour from different geographical areas, expressed by percentage contribution per individual $10^{\circ} \times 5^{\circ}$ grid boxes. Panel (d) shows longitudinal distribution of the water vapour entry, i.e. the value from (c) integrated over latitude $\left(30^{\circ} \mathrm{N}-30^{\circ} \mathrm{S}\right)$ per $60^{\circ}$ longitude. The results from kinematic calculations, based on ERA-40 reanalysis data, are very similar.

\section{Results and discussion}

\subsection{NH Winter 1995-1996}

Figures 2, 3 and 4 show results from the NH winter 19951996 (neutral ENSO). The reference calculations (those based on ERA-40 reanalysis data) are shown in Fig. 2, while Figs. 3 and 4 contain the results from the calculations based on the CCMs. The geographical distribution of dehydration points is shown in the panels (a) and (b), respectively. The colors in panel (a) depict the cold point temperatures; panel (b) shows the corresponding equilibrium water vapour mixing ratio. Note that the values from FUB (Fig. 4b) are divided by a factor of two to match up with the common color scale.

In order to make an assessment of the contribution of the different geographical regions to the overall stratospheric

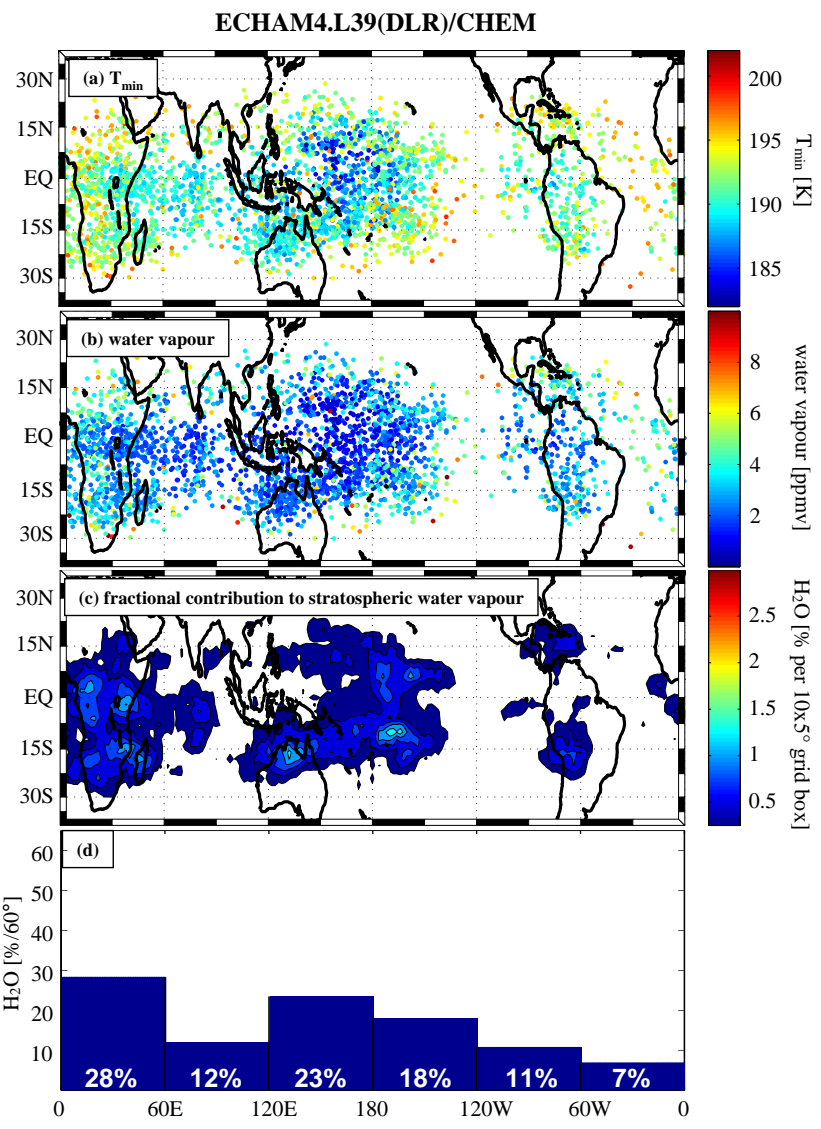

Fig. 3. As in Fig. 2, for ECHAM4.L39(DLR)/CHEM.

water vapour, the investigation area was divided in $10^{\circ} \times 5^{\circ}$ (longitude $\times$ latitude) grid boxes. The trajectories reaching their individual dehydration points in a grid cell are identified. The total water vapour transported into the stratosphere by these trajectories was divided by the overall water vapour transported into the stratosphere by all TS trajectories. This fraction is shown in panels (c) of the figures. Hence, the numbers shown there represent the fraction of water molecules in the stratosphere that encountered their last contact with the ice phase in the respective geographical region. Since temperatures during the last contact with the ice phase determine water vapour mixing ratios that remain in the gas phase, stratospheric water vapour mixing ratios are particularly sensitive to temperatures in regions where the values shown in panels (c) are large. Panels (d) illustrate the longitudinal distribution of the water vapour entry, i.e. the values from (c) integrated over all latitudes (from $30^{\circ} \mathrm{N}$ to $30^{\circ} \mathrm{S}$ ) per $60^{\circ}$ longitude bin. The arrangement of these panels does not change for the other years/seasons.

In the neutral NH winter 1995-1996, the reference calculations (Fig. 2) indicate that the region with particularly low temperatures occurs over the West Pacific (here defined between $120^{\circ}$ E and $180^{\circ}$ ), seen in Fig. 2a. Figure $2 b$ shows that the dehydration points in the West Pacific have equilibrium 


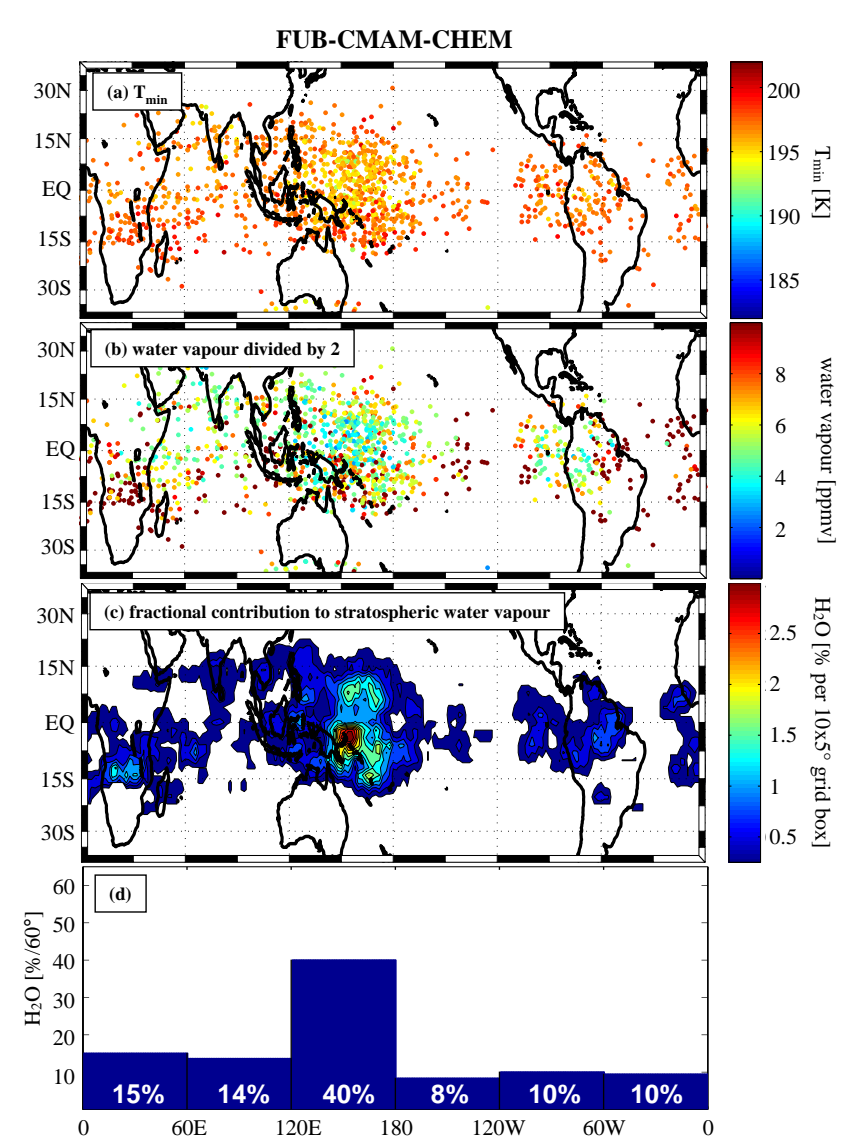

Fig. 4. As in Fig. 2, for FUB-CMAM-CHEM.

water vapour mixing ratios lower than $\sim 2$ ppmv. These values increase to the west and east but do not exceed 5 ppmv. The mean mixing ratio over all TS trajectories in the reference calculation is $2.6 \mathrm{ppmv}$. In $\mathrm{NH}$ winter, water vapour mixing ratios of about $2.5-3.0 \mathrm{ppmv}$ are typically observed in the lower stratosphere (Bonazzola and Haynes, 2004). Figure $2 \mathrm{~d}$ shows that the Western Pacific contributed $44 \%$ to the entire stratospheric water vapour. Contributions from South America and Africa are much smaller (below 15\%). Our calculations with kinematic trajectories (not shown) give similar results but the concentration of dehydration points over the West Pacific is somewhat less pronounced (32\% contribution). The kinematic results are virtually identical to the results from Fueglistaler et al. (2004).

Figure 3 shows results from E39/C. The temperatures at the dehydration points (and likely in most of the TTL) are overestimated by about $5 \mathrm{~K}$, leading to an average positive bias of water vapour mixing ratios of 2.5 ppmv over all TS trajectories. However, the geographical distribution of the dehydration points (Fig. 3a, b) is fairly well reproduced compared to the reference calculations, though the distribution is more zonally symmetric and the concentration of points over Africa is larger than in the reference. Since temperatures are higher there, the fractional contribution of Africa (here de-

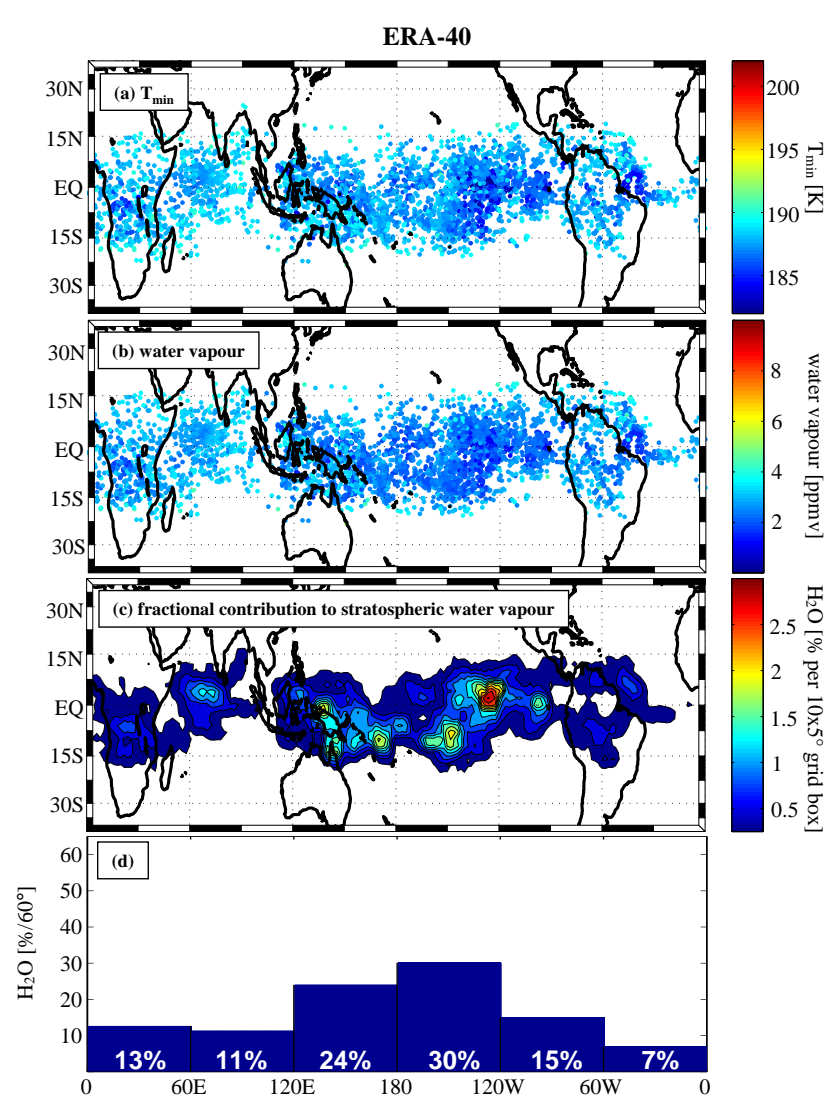

Fig. 5. As in Fig. 2, for NH winter 1997-1998 (El Niño).

fined between $0^{\circ}$ and $60^{\circ} \mathrm{E}$ ) to stratospheric water vapour is overestimated ( $28 \%$ versus $15 \%$ in the reference).

Results from FUB-CMAM-CHEM are shown in Fig. 4. The minimum temperatures are overestimated by about $9 \mathrm{~K}$ results in a positive bias of average water vapour of more than a factor of three. But the geographical distribution of dehydration points is in good agreement with the reference calculation and the location of the minimum temperatures are better reproduced than in E39/C (Fig. 4a, b). The fractional contributions of the different geographical areas (Fig. 4d) are similar to the reference.

Due to the warm temperature bias of the CCMs in the TTL, the overall water vapour flux into the stratosphere is too high, an effect that is particularly pronounced in FUBCMAM-CHEM. But the relative importance of the different geographical regions for determining stratospheric water vapour is overall well represented.

\subsection{NH winter 1997-1998}

The distributions of dehydration points and the distribution of water vapour entry during the "warm" ENSO phase (El Niño) are presented in Figs. 5, 6 and 7. During El Niño the main convective region in the Pacific is shifted eastward and covers the Central and Eastern Pacific. 


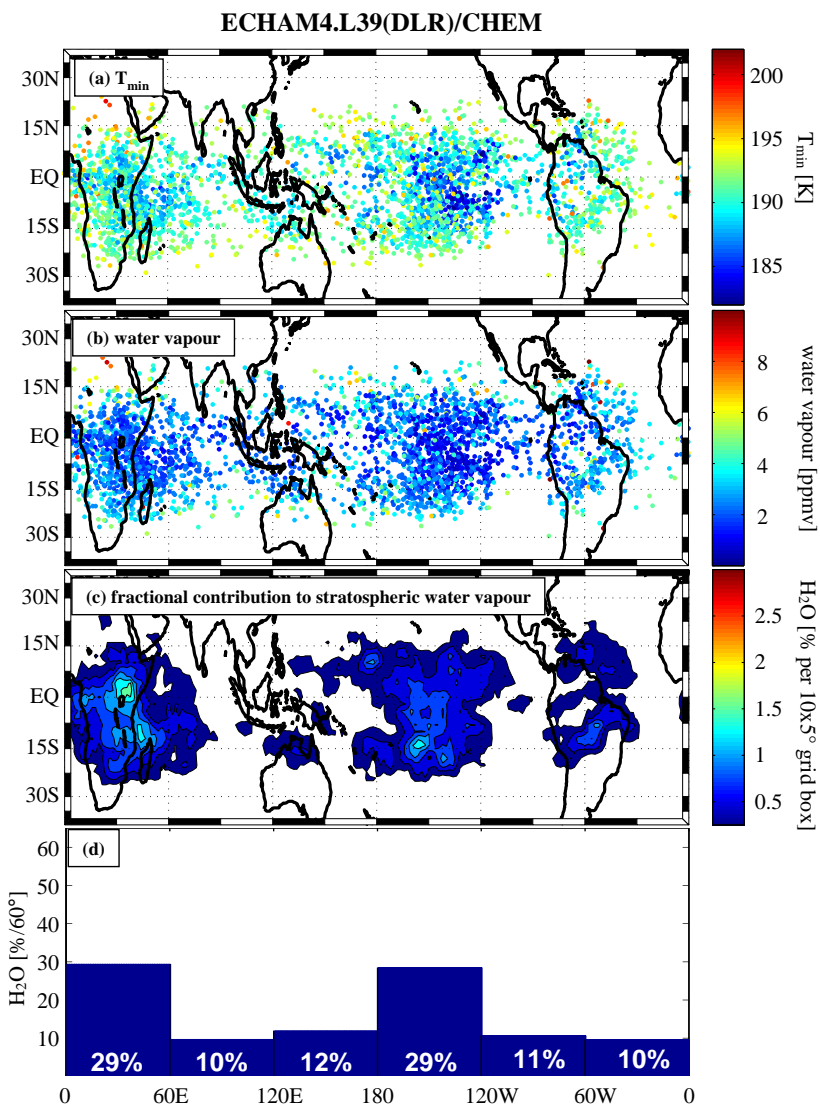

Fig. 6. As in Fig. 2, for ECHAM4.L39(DLR)/CHEM and NH winter 1997-1998 (El Niño).

The effect of ENSO on the water vapour transport and the geographical distribution of dehydration points is also discussed and explained in Fueglistaler and Haynes (2005).

In the reference calculation (Fig. 5) the geographical distribution of dehydration points is significantly more zonally symmetric during El Niño compared to the neutral $\mathrm{NH}$ winter 1995-1996. Enhanced densities of points occur in the Central and East Pacific (here defined from $180^{\circ}$ to $120^{\circ} \mathrm{W}$ ). The region of lowest temperatures is shifted eastward (following the displacement of the convection during the El Niño event) and is also located over the Central and East Pacific. Accordingly the lowest water vapour mixing ratios occur here (Fig. 5b). The Central and East Pacific contribute 30\% of the overall water vapour that gets into the stratosphere during the El Niño winter, while the contribution from the West Pacific drops to $24 \%$. The mean water vapour mixing ratio is 2.5 ppmv, which does not differ significantly from the mean mixing ratio in the neutral NH winter 1995-1996. These results suggest that during the El Niño event the amount of water entering the stratosphere is not increased relative to the NH winter 1995-1996, but the locations of the dehydration points change significantly.

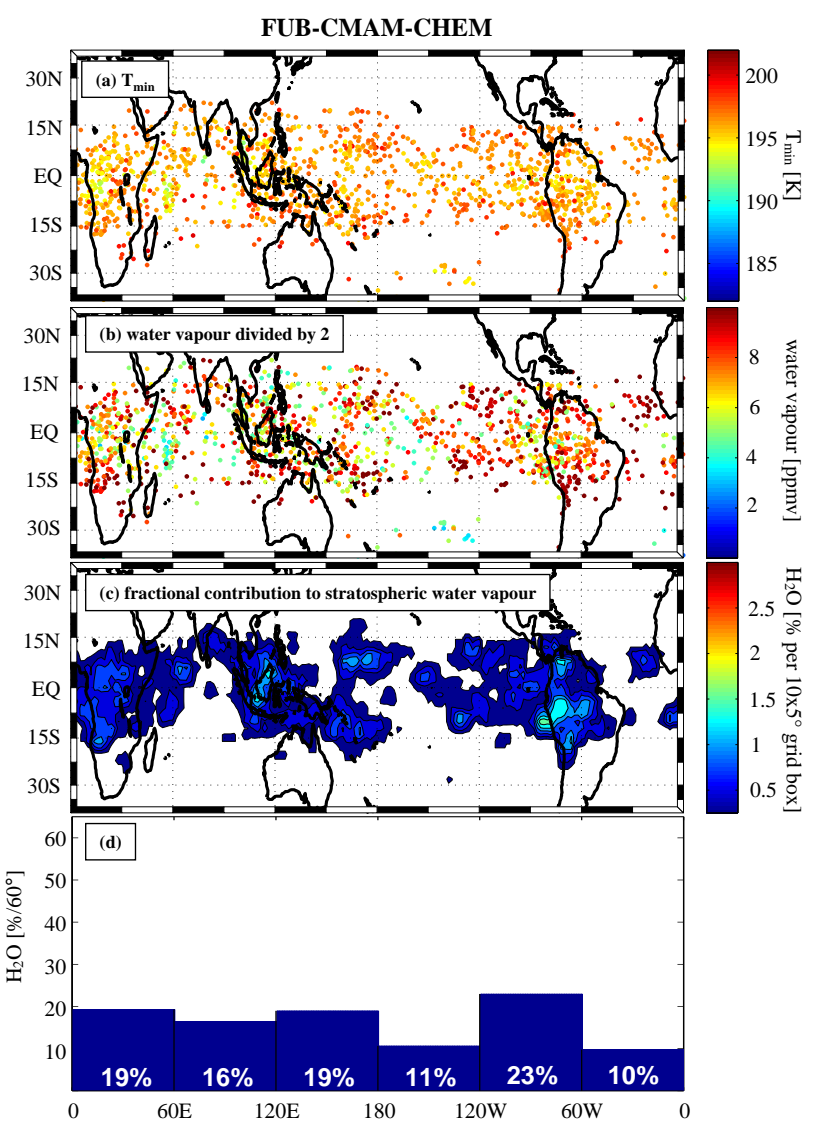

Fig. 7. As in Fig. 2, for FUB-CMAM-CHEM and NH winter 19971998 (El Niño).

Figure 6 shows results from E39/C. Temperature and water vapour biases are slightly smaller than for the neutral year. The shift of the geographical distribution of dehydration points to the Central and East Pacific is well reproduced. However the contribution of Africa is too high (29\% compared to $13 \%$ in the reference), as was also the case in the neutral year. In contrast to the reference where the Central and East Pacific contribute the main amount of water vapour to the entire water vapour transport, in E39/C the contribution of Africa and Central and East Pacific is the same.

Results from FUB-CMAM-CHEM are shown in Fig. 7. The temperature bias is similar as in the neutral year, resulting in more than a factor of five bias in water vapour (14.8 ppmv versus $2.5 \mathrm{ppmv}$ in the reference). As in the reference the geographical distribution of dehydration points is more zonally symmetric, and the region of water vapour entry into the stratosphere is shifted eastward. The strongest water vapour entry occurs in the most eastern part of the $\mathrm{Pa}$ cific, stretching into the South American continent (contribution of 23\%). Hence the eastward shift of water vapour entry during El Niño is overestimated by the FUB-CMAMCHEM. 
Particularly, the higher density of dehydration points over Africa and South America in the CCMs and the higher temperatures and thus higher mixing ratios there lead to overall excessive water vapour entry into the stratosphere compared to the reference.

\subsection{NH winter 1998-1999}

The NH winter 1998-1999 corresponds to La Niña conditions (cold ENSO phase). During the La Niña event the region of convection is shifted slightly westward compared to neutral conditions. Results from this year are shown in Figs. 8, 9 and 10.

In the reference calculations (Fig. 8) the dehydration points are even more concentrated over the West Pacific with less contributions from Africa and South America compared to the neutral winter. Also, the TS trajectories experienced lower temperature minima than in the other years. Some of the TS trajectories reach temperature minima of $\sim 175 \mathrm{~K}$. The coldest region and thus lowest water vapour mixing ratios are found over the West Pacific. Due to the lower temperatures, the mean water vapour mixing ratio is also lower than in the other years (1.5 ppmv versus $2.5-2.6 \mathrm{ppmv})$. The very low water vapour mixing ratios are in rough agreement with water vapour profile observations by MacKenzie et al. (2006) from the same winter. During this La Niña the contribution of stratospheric water vapour is even more focussed on the West Pacific (60\%) (Fig. 8d).

In E39/C (Fig. 9) the overall drop in TTL temperatures between neutral conditions and the La Niña is not reproduced, nor the geographical distribution of dehydration points during this La Niña event. The maximum density of dehydration points is shifted eastwards towards the Central Pacific compared to the westward shift in the reference. Overall the distribution is much too zonal and water vapour contributions from Africa and South America are too high (e.g. 32\% from Africa and only $22 \%$ from the West Pacific, compared to $11 \%$ and $60 \%$ in the reference). A plausible explanation for the discrepancy between E39/C results and the analyses derived from ERA-40 is that in the E39/C simulation the SSTs for the period after January 1999 were artificially produced by using monthly mean values of the years 1996 to 1998 because of the lack of observations at the time when running the model simulation.

In FUB-CMAM-CHEM (Fig. 10) the temperature and water vapour biases are similar as in the neutral year. Nevertheless, the distribution of dehydration points and the westward shift of the maximum density are fairly well reproduced. The largest difference between the reference and FUB-CMAMCHEM is that in the latter more trajectories reach their temperature minimum over the warmer regions of Africa and the Indian Ocean, which contributes to the positive water vapour bias. The dominant contribution of stratospheric water vapour from the West Pacific is slightly less pronounced ( $42 \%$ versus $60 \%$ in the reference).

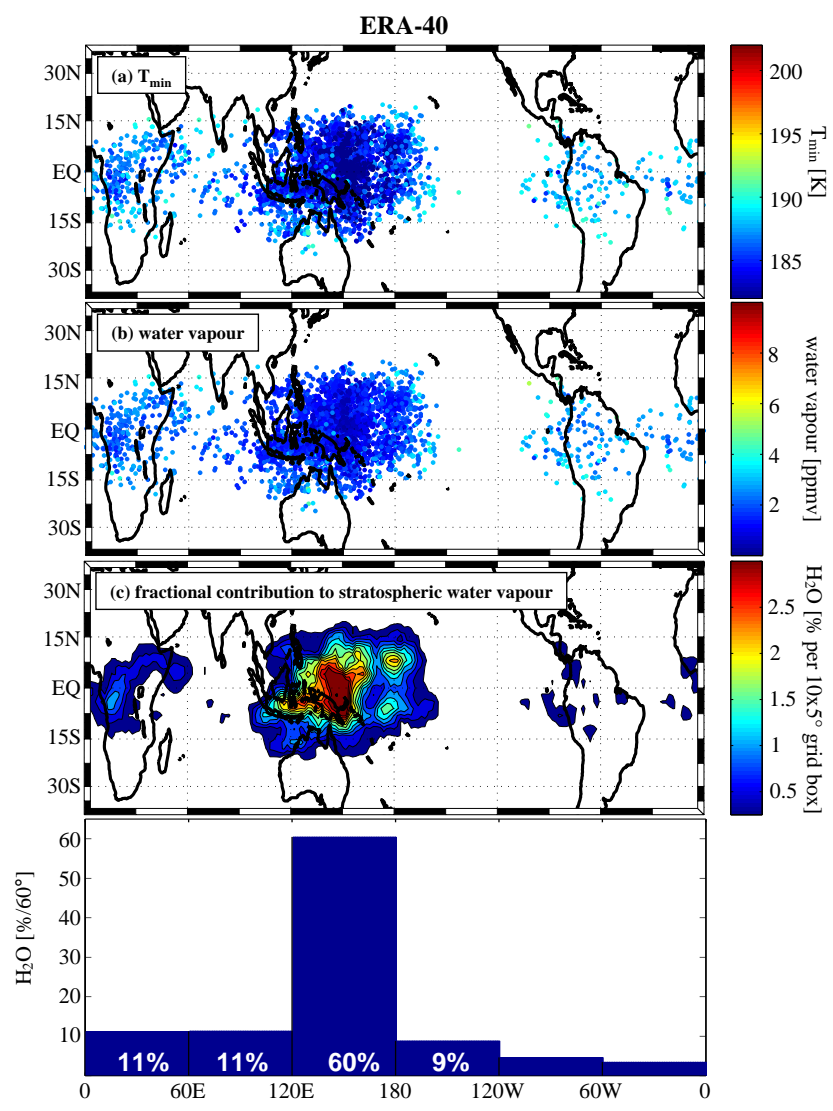

Fig. 8. As in Fig. 2, for NH winter 1998-1999 (La Niña).

The westward shift of dehydration points and the larger concentration of points in the maximum over the West Pacific are reproduced by one CCM (FUB-CMAM-CHEM), while the other does not represent the changes in this pattern during La Niña.

\subsection{NH Summer}

The location of the intertropical convergence zone (ITCZ) varies with the seasons. Over land it shifts from the Southern Hemisphere ( $\mathrm{SH})$ in $\mathrm{NH}$ winter to the $\mathrm{NH}$ in $\mathrm{NH}$ summer. Over the Pacific and Atlantic ocean the ITCZ does not vary that much with the seasons. The Indian monsoon is connected with the seasonal shift of the ITCZ. Trajectories are calculated for the NH summers 1996, 1997 and 1998 in order to examine the seasonal variations of water vapour transport and the influence of the Indian monsoon on the transport processes in the TTL. Only the results of the NH summer 1996 are presented here.

The reference results for NH summer are shown in Fig. 11. With respect to the NH winters, TS trajectories assumed temperature minima are about $4 \mathrm{~K}$ higher. Due to higher temperature minima the mean water vapour mixing ratio (3.8 ppmv) is higher than in $\mathrm{NH}$ winter. This value agrees well with the observed values of about 3.5-4.5 ppmv (Bonazzola and 


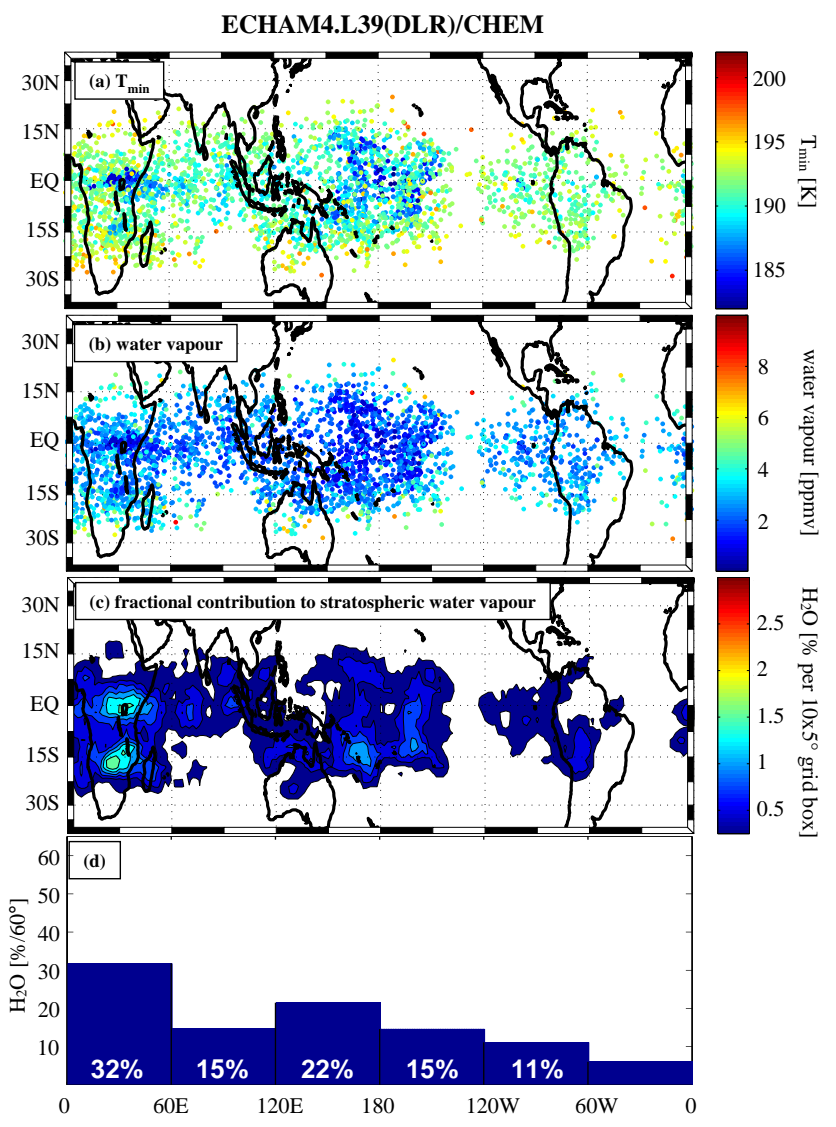

Fig. 9. As in Fig. 2, for ECHAM4.L39(DLR)/CHEM and NH winter 1998-1999 (La Niña).

Haynes, 2004). The regions of lowest temperatures are found over Indonesia, Philippines and the Bay of Bengal (Fig. 11a). In contrast to $\mathrm{NH}$ winter, a large number of dehydration points lie outside the region between $15^{\circ} \mathrm{N}$ and $15^{\circ} \mathrm{S}$. Overall the region of dehydration points is shifted northward, with points lying as far north as $30^{\circ} \mathrm{N}$. This shift follows the seasonal shift of the ITCZ in NH summer. Since relatively high temperatures coincide with a large density of dehydration points over the Bay of Bengal, this region contributes a large fraction of the overall water vapour transport into the stratosphere. The West Pacific and the India/Indian Ocean region $\left(60^{\circ} \mathrm{E}\right.$ to $\left.120^{\circ} \mathrm{E}\right)$ both contribute $36 \%$ to the entire water vapour entry in ERA-40 (Fig. 11d). The geographical distribution of the water vapour entry suggests that the Indian monsoon affects the water vapour transport into the stratosphere.

In E39/C (Fig. 12) the summertime temperature bias in the TTL is less pronounced than in winter $(+3 \mathrm{~K})$. The temperatures in the dehydration points and corresponding water vapour are much more variable than during winter and than in the reference calculation. Much too warm and wet dehydration points occur particularly at the edge of the tropics in the NH but also above Africa. There is still a positive bias

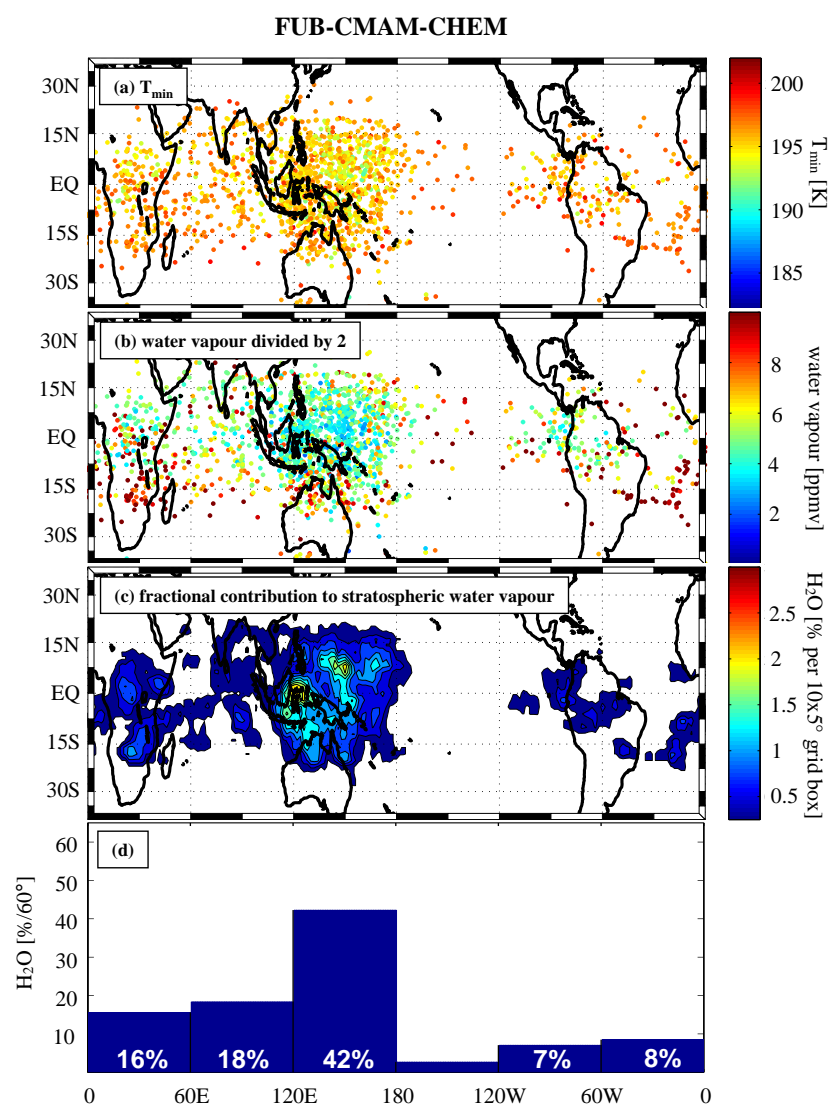

Fig. 10. As in Fig. 2, for FUB-CMAM-CHEM and NH winter 1998-1999 (La Niña).

in overall water vapour entry into the stratosphere, however due to the smaller temperature bias compared to the $\mathrm{NH}$ winters is the positive water vapour bias in $\mathrm{NH}$ summer smaller than in winter ( 2 ppmv positive bias versus $2.5 \mathrm{ppmv}$ positive bias in winter 1995-1996). The contribution from the Indian monsoon is not reproduced and the maximum density of points lies too far east over the Pacific. Accordingly the contribution from the Indian/Indian Ocean sector is too low (17\% compared to $36 \%$ in the reference). The contribution from Africa is about $12 \%$ higher than in the reference.

In FUB-CMAM-CHEM (Fig. 13) the high temperature bias of about $3 \mathrm{~K}$ is much smaller than in all $\mathrm{NH}$ winters, leading to a lower mean water vapour mixing ratio of about $7.1 \mathrm{ppmv}$. The cold point temperatures are roughly 2 to $3 \mathrm{~K}$ lower than in the $\mathrm{NH}$ winters. The reason for that requires further investigations and is beyond the scope of this paper.

Consistent with the reference calculations the region of lowest temperatures shifts north-westward and overall the distribution of dehydration points is fairly well reproduced with the lowest temperature minima and water vapour mixing ratios over the Arabian Sea, India and the Bay of Bengal. As in E39/C, individual warm and wet dehydration points lie at the southern edge of the tropics and are scattered throughout 


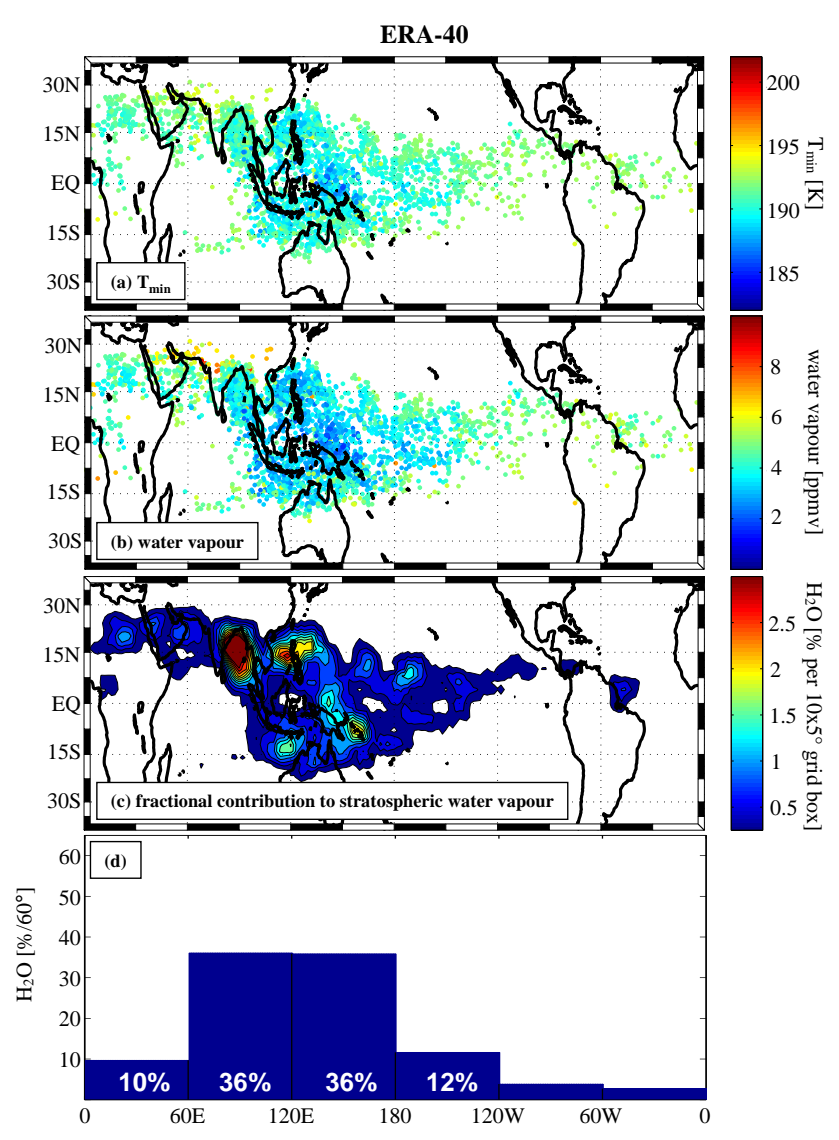

Fig. 11. As in Fig. 2, for NH summer 1996.

the tropics. The impact of the Indian monsoon is reproduced but is less pronounced than in the reference. Figure 13d shows that the region India/Indian Ocean contributes $51 \%$ to the entire stratospheric water vapour entry, which is a higher contribution than in the reference. But note that while in the reference virtually all water vapour transport in this sector takes place over India, in FUB-CMAM-CHEM a significant contribution to the entire water vapour transport comes from the region over the Southern Indian Ocean.

Overall the fields of water vapour carried through the dehydration points in both CCMs appear to be more noisy than in the reference (panels b of Figs. 11-13). Otherwise important features of the geographical distribution of dehydration in summer (e.g. the importance of the Indian monsoon) are fairly well reproduced by FUB-CMAM-CHEM but not by E39/C.

\subsection{Residence time}

The periods that trajectories spend in the upper TTL $(\Theta=385-395 \mathrm{~K})$ are derived from the trajectory calculations. Results of the neutral NH winter 1995-1996 and NH summer 1996 are presented. The results of the other years are similar.

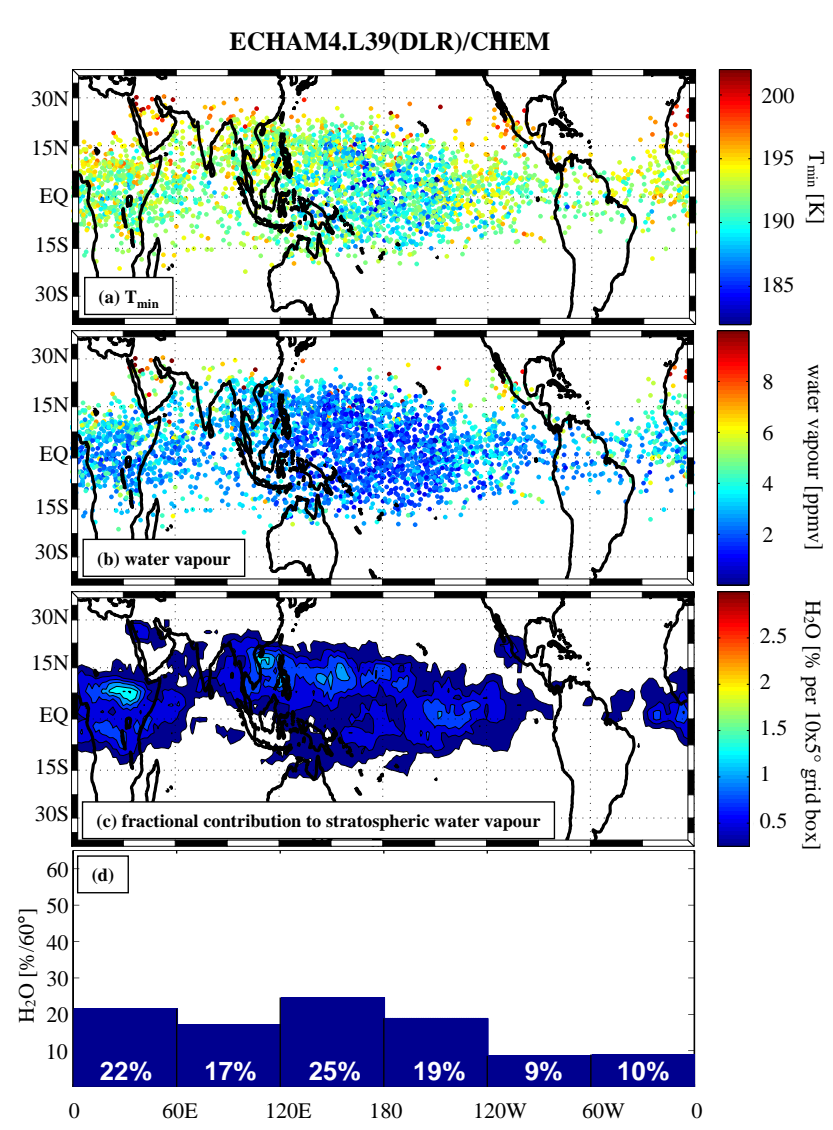

Fig. 12. As in Fig. 2, for ECHAM4.L39(DLR)/CHEM and NH summer 1996.

Figures 14 and 15 show histograms of the PDF of the residence time in the upper TTL for NH winter 1995-1996 and for NH summer 1996 respectively. The first panel shows the results of the reference calculation and the second the results from kinematic calculations based on ERA-40 data. The results based on CCM data are shown in the third (E39/C) and fourth panel (FUB).

Figure 14 shows that on average the reference trajectories stay longer in the upper part of the TTL than the kinematic trajectories, no matter which data set is used to drive these. The difference is most pronounced for the kinematic trajectories based on ERA-40 data, which is consistent with the notion of Schoeberl et al. (2003) that assimilation models tends to produce noisier vertical wind fields than free running GCMs.

The most important difference between the different panels is the shape of the PDF. The majority of the reference trajectories reside 9-10 days in the upper TTL before they leave this layer. Only very little air masses pass through this layer in less than 5 days. In contrast transport that is based on vertical winds (i.e. the transport in the CCMs) results in residence times that are mostly shorter than 5 days. The basic difference in the shape of the PDF compared to the reference 


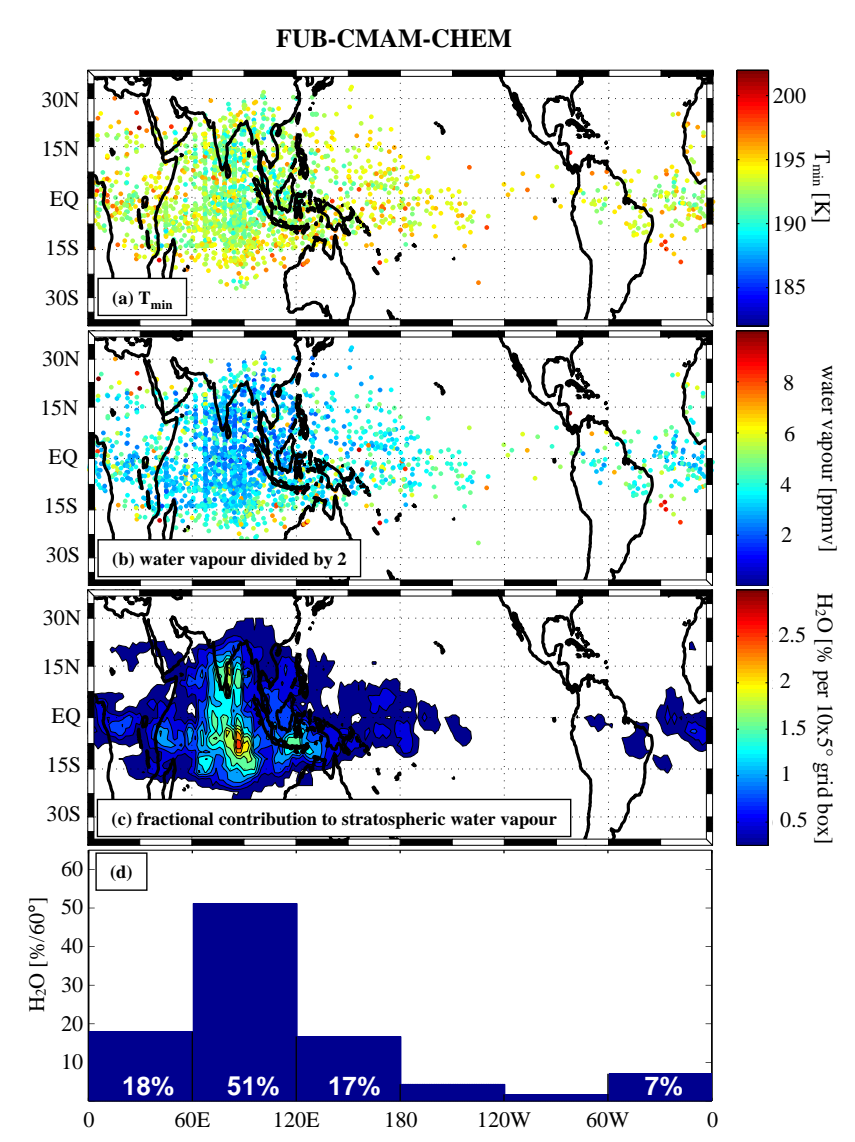

Fig. 13. As in Fig. 2, for FUB-CMAM-CHEM and NH summer 1996.

is presented in both, summer and winter. This has a crucial influence on the transport of short-lived chemical species through the TTL. In the CCMs more short-lived compounds can reach the stratosphere chemically unaltered compared to the reference.

The comparison between panels 1 and 2 shows that this discrepancy mostly comes from the use of vertical winds to drive the transport in CCMs and a very similar discrepancy also shows up between kinematic calculations based on ERA-40 data and the more realistic reference calculations (diabatic calculations based on ERA-40).

In $\mathrm{NH}$ summer the reference trajectories stay longer in the upper TTL than in NH winter (Fig. 15 compared to Fig. 14). This is expected from the seasonal variation of the BDC. This seasonal variation of ascent rates through the TTL is not reproduced by both CCMs, which show similar average residence times in summer and winter. As the seasonal cycle of residence times in the TTL is also reduced in the kinematic calculations based on ERA-40 data. This implies a different relevance of the seasonal cycle for the heating rates and the vertical winds.
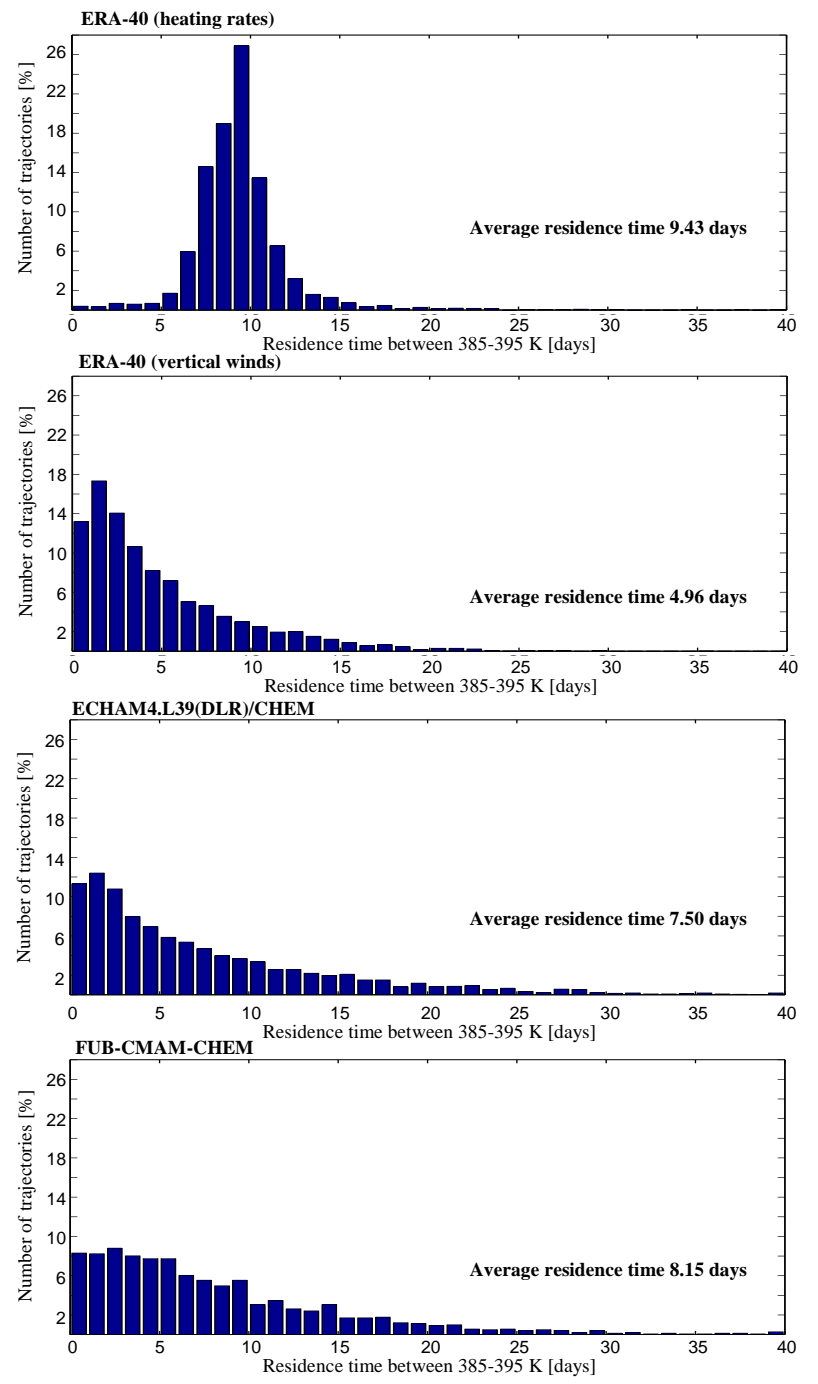

Fig. 14. NH winter 1995-1996. Residence time for the TS trajectories in the upper part of the TTL for ERA-40 (heating rates) (top), ERA-40 (vertical wind) ECHAM4.L39(DLR)/CHEM and FUBCMAM-CHEM (bottom), respectively.

\section{Summary}

Lagrangian trajectory studies are now established tools for studying processes that regulate the transport of water from the troposphere into the stratosphere through the TTL. Here we have used this method to evaluate how well these processes are represented by two state of the art CCMs. In contrast to previous work diabatic trajectories driven by meteorological reanalysis data have been used to give the best representation of the processes in the real atmosphere. The results of these reference calculations agree reasonably well with studies based on kinematic trajectories (Fueglistaler et al., 2004); Bonazzola and Haynes (2004) showing that the main conclusions of these papers are fairly robust and do not depend much on the method that is used to drive the 

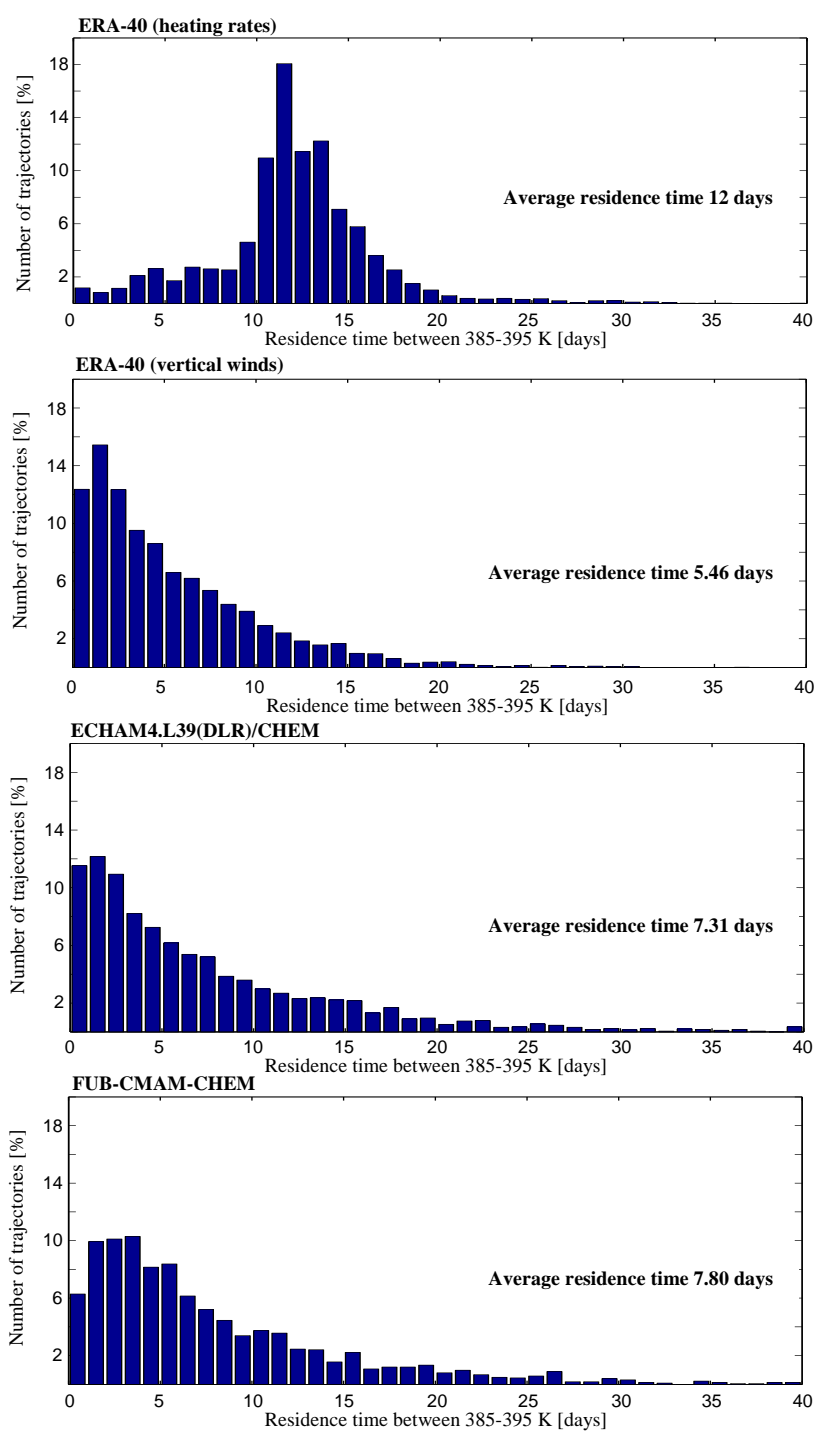

Fig. 15. As in Fig. 14, for NH summer 1996.

vertical transport. In particular the notion that during neutral and La Niña years most dehydration takes place over the West Pacific and that this regions shifts toward the Central and East Pacific during El Niño is confirmed by our diabatic calculations.

For all years analysed, both CCMs have a warm temperature bias of about $5 \mathrm{~K}$ (E39/C) and $9 \mathrm{~K}$ (FUB-CMAMCHEM) in $\mathrm{NH}$ winter and about $3 \mathrm{~K}$ (both CCMs) in $\mathrm{NH}$ summer compared to the reference calculations. Thus the overall water vapour entry into the stratosphere is too high relative to ERA-40. This seems to be a general feature of simulations with models of the ECHAM family, as is also shown in Eyring et al. (2006), and thus seems rather to be due to deficits in the physical parameterizations than to the differences in the spatial resolutions of the two CCMs.

In NH winter 1995-1996 (neutral ENSO phase) the mean mixing ratio over all trajectories in $\mathrm{E} 39 / \mathrm{C}$ is $5.5 \mathrm{ppmv}$ and in FUB-CMAM-CHEM 13 ppmv, compared to the reference calculation of $2.6 \mathrm{ppmv}$. The value from the reference run compares well with the observed values. But the geographical distribution of dehydration points is fairly well represented by both CCMs, particularly by FUB-CMAM-CHEM, while E39/C shows somewhat more dehydration over Africa than the reference calculation.

During the El Niño winter 1997-1998 the shift of the dehydration region to the east is well reproduced in E39/C. In FUB-CMAM-CHEM the strong dehydration in the Central and East Pacific of the reference calculation is shifted eastwards. Both CCMs show a higher density of dehydration points over Africa where temperatures are higher. This contributes to overall excessive water vapour transport into the stratosphere relative to the reference calculation. The mean water vapour mixing ratio is $5 \mathrm{ppmv}(\mathrm{E} 39 / \mathrm{C})$ and $14.8 \mathrm{ppmv}$ (FUB-CMAM-CHEM) compared to $2.5 \mathrm{ppmv}$ in the reference.

During La Niña (NH winter 1998-1999) minimum temperatures and water vapour mixing ratios are lower than in the other years, resulting in average water vapour of $1.5 \mathrm{ppmv}$. This drop in temperature and water vapour is not reproduced in E39/C, neither is the geographical distribution of dehydration reproduced relative to the reference calculation. Overall the distribution is much too zonal and water vapour contributions from Africa are too high compared to the reference. The mean water vapour mixing ratio is $5.1 \mathrm{ppmv}$, partly caused by the artificially constructed SSTs after January 1999 in the E39/C simulation. In FUBCMAM-CHEM the mean temperature is $1 \mathrm{~K}$ lower and the mean water vapour is 2 ppmv lower than in the neutral winter. The distribution of dehydration points and the westward shift of the maximum density are fairly well reproduced in this model, compared to the reference calculation. It should however be noted, that single El Niño and La Niña events are analysed here and details of the simulated features for the different ENSO phases might differ from a mean ENSO signal.

In NH summer 1996 all trajectories reach higher temperature minima than in $\mathrm{NH}$ winter, except the trajectories based on FUB-CMAM-CHEM data. Consequently, the amount of water vapour reaching the stratosphere is higher than in $\mathrm{NH}$ winter. The mean water vapour mixing ratios are $5.8 \mathrm{ppmv}$ (E39/C) compared to $3.8 \mathrm{ppmv}$ in the reference calculations. In the FUB-CMAM-CHEM the mean temperatures are about 1-3 K lower than in the $\mathrm{NH}$ winters, thus the amount of water vapour entering the stratosphere is in that case lower than in all $\mathrm{NH}$ winters ( $7.1 \mathrm{ppmv}$ compared to all winters $\geq 10 \mathrm{ppmv}$ ). The reason for that special feature needs further investigations and is at that point beyond the scope of this paper. Nevertheless, the important features of the geographical distribution of dehydration (e.g. the importance of the Indian monsoon) are fairly well reproduced by FUBCMAM-CHEM but not by E39/C. 
The residence times in the upper TTL $(\Theta=385-395 \mathrm{~K})$ are determined. It turns out that in contrast to the geographical distribution of dehydration, the residence times are very sensitive to the approach that is used for driving the vertical transport (heating rates versus vertical winds). Since diabatic trajectories, which are based on heating rates, best represent real atmospheric conditions (e.g., Wohltmann and Rex, 2008) but vertical transport is driven by vertical winds in the CCMs, significant differences between the PDF of the residence times exist between the reference calculation and the CCM results. In the reference, virtually all air masses remain 6 days or longer in the vertical range indicated above, while in the CCM based runs most air masses remain 5 days or less in this region. Also, the seasonal cycle of the residence time (with slower ascent and longer residence times in $\mathrm{NH}$ summer) is not reproduced by the CCMs. The same deficit applies to trajectory studies that are driven by meteorological reanalysis data but which are based on vertical winds.

\section{Discussion}

In this study we could demonstrate the usefulness of simple diagnostic models, as for example, Lagrangian trajectory calculations, to evaluate the performance of complex CCMs. It turned out that the two CCMs of this study have different transport characteristics in the TTL leading to different regions of water vapour entry into the stratosphere and water vapour concentrations in the lower stratosphere. There are a number of possible explanations for the transport differences. Both CCMs belong to the ECHAM family of general circulation models (GCMs) originally developed at the Max-Planck-Institute for Meteorology, Hamburg, and have the same dynamical core. However, they include different developments of the physical parameterizations, e.g. the short-wave radiation code or convection schemes. E39/C is run with higher horizontal and vertical resolution (in the upper troposphere/lower stratosphere (UTLS)), while FUBCMAM-CHEM resolves the full stratosphere and mesosphere (in contrast to E39/C which has the upper lid at $10 \mathrm{hPa}$ (about $30 \mathrm{~km}$ ) in the middle stratosphere).

The large temperature bias in the TTL in both CCMs leads to unrealistic absolute values in the transport of water vapour into the stratosphere. The larger warm bias in the tropopause cold point temperature of FUB-CMAM-CHEM is partly due to the coarser vertical resolution in the tropical TTL compared to E39/C. Cold point temperature biases are a common deficit of current CCMs, as shown in Fig. 16. Long-term mean tropical temperature profiles in the UTLS are displayed for two reanalysis data sets (ERA-40 and NCEP/NCAR) and 13 state-of-the-art CCMs. The CCM data (except for FUBCMAM-CHEM) are taken from the transient CCMVal REF1 simulations of the past and averaged over the $\mathrm{NH}$ winters (DJF) of the period 1980/1981 to 1998/1999. For more details of the CCMs and the set up of the simulations see Eyring

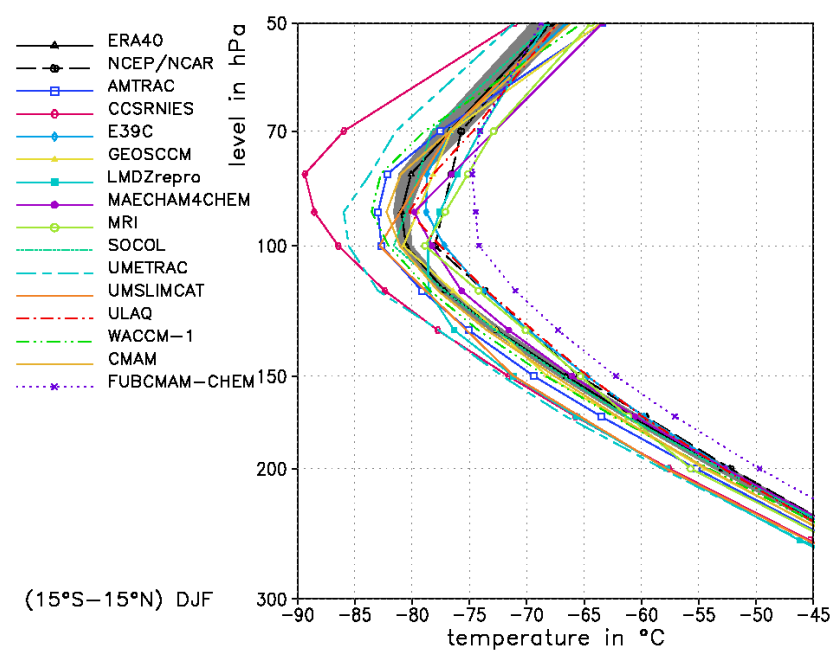

Fig. 16. Tropical temperature in the UTLS (between $300 \mathrm{hPa}$ and $50 \mathrm{hPa}$ ) in Northern winter (DJF) averaged between $15^{\circ} \mathrm{S}$ and $15^{\circ} \mathrm{N}$ and over the period 1980/1981-1998/1999 for ERA-40 and NCEP/NCAR reanalysis and 13 state-of-the-art CCMs. Grey shading indicates the 1 standard deviation of ERA-40.

et al. (2006). The CCM temperatures show a large spread of the cold point tropopause temperature of up to $11 \mathrm{~K}$ between the coldest and the warmest model. Compared to the observations, biases of up to $6 \mathrm{~K}$ occur. Note that also a bias exists between the two observational datasets reaching several degrees at the cold point tropopause and exceeding the $1-\sigma$ standard variation of the ERA-40 dataset. These results together with those of the two CCMs used in our work illustrate the need to improve the simulation of the temperature distribution in the tropical upper troposphere and the TTL in CCMs in order to achieve a realistic magnitude of water vapour transport into the stratosphere. Very recently Stenke et al. (2008) demonstrated the importance of the respective advection scheme for the transport of water vapour, cloud water and chemical trace species used in an interactively coupled model like a CCM. They showed that using a purely Lagrangian (numerically non-diffusive) algorithm in E39/C instead of a semi-Lagrangian scheme significantly reduces the temperature biases in the tropics and extra-tropics (see Fig. 3 from Stenke et al., 2008). Consequently, the wet bias particularly in the tropics is clearly reduced in this upgraded model version. Further work is currently going on within the CCMVal activity to address these issues.

The differences in the geographical distribution of the dehydration points between the two CCMs arise from the convection schemes as well as the SSTs prescribed in the transient simulations. As already discussed, the areas of strongest water vapour transport into the stratosphere correspond with the areas of strongest deep convection in the tropics. While FUB-CMAM-CHEM uses the Kuo scheme (Kuo, 1974), which is a convective adjustment convection 
parametrization, E39/C includes a mass-flux scheme originally developed by Tiedtke (1989). Nissen et al. (2000) showed that the different initialization criteria for deep convection in these two schemes lead to differences in the structure of latent heat release. Further, the intensity and location of deep convection is steered by the tropical SSTs. This effect is clearly visible in the longitudinal shift of the main convective regions in the CCMs for the different ENSO phases. Discrepancies between the CCMs can partly be explained by differences in prescribed SSTs.

Acknowledgements. We thank Stefan Fueglistaler and one anonymous reviewer for valuable comments. We would like to thank Rudolf Deckert for providing the ECHAM4.L39(DLR)/CHEM model data. We want to thank the SCOUT-O3 modelling groups for agreeing to display their CCM results in Fig. 16. We thank Lee Grenfell and Peter Mieth for contributing to the development of the FUB-CMAM-CHEM model and for performing the simulation. The FUB-CMAM-CHEM simulations have been performed within the European project EuroSPICE (EVK2-CT-1999-00014) at the Konrad-Zuse-Zentrum für Informationstechnik, Berlin. The analysis has been supported by the European project SCOUT-O3 (GOCE-CT-2004-505390). Meteorological data were provided by the European Centre for Medium-Range Weather Forecasts (ECMWF).

Edited by: R. MacKenzie

\section{References}

Bonazzola, M. and Haynes, P.: A trajectory-based study of transport and dehydration in the tropical tropopause, J. Geophys. Res., 109, D20112, doi:10.1029/2003JD004356, 2004.

Brewer, A. W.: Evidence for a world circulation provided by measurements of $\mathrm{He}$ and $\mathrm{H}_{2} \mathrm{O}$ in the stratosphere, Q. J. Roy. Meteor. Soc., 75, 351-363, 1949.

Christensen, T., Knudsen, B. M., Pommereau, J.-P., Letrenne, G., Hertzog, A., Vial, F., Ovarlez, J., and Piot, M.: Evaluation of ECMWF ERA-40 temperature and wind in the lower tropical stratosphere since 1998 from past long-duration balloon measurements, Atmos. Chem. Phys., 7, 3399-3409, 2007, http://www.atmos-chem-phys.net/7/3399/2007/.

Dameris, M., Grewe, V., Ponater, M., Deckert, R., Eyring, V., Mager, F., Matthes, S., Schnadt, C., Stenke, A., Steil, B., Brühl, C., and Giorgetta, M. A.: Long-term changes and variability in a transient simulation with a chemistry-climate model employing realistic forcing, Atmos. Chem. Phys., 5, 2121-2145, 2005, http://www.atmos-chem-phys.net/5/2121/2005/.

Eyring, V., Butchart, N., Waugh, D. W., Akiyoshi, H., Austin, J., Bekki, S., Bodeker, G. E., Boville, B. A., Brühl, C., Chipperfield, M. P., Cordero, E., Dameris, M., Deushi, M., Fioletov, V. E., Frith, S. M., Garcia, R. R., Gettelman, A., Giorgetta, M. A., Grewe, V., Jourdain, L., Kinnison, D. E., Mancini, E., Manzini, E., Marchand, M., Marsh, D. R., Nagashima, T., Newman, P. A., Nielsen, J. E., Pawson, S., Pitari, G., Plummer, D. A., Rozanov, E., Schraner, M., Shepherd, T. G., Shibata, K., Stolarski, R. S., Struthers, H., Tian, W., and Yoshiki, M.: Assessment of temperature, trace species, and ozone in chemistry-climate model simulations of the recent past, J. Geophys. Res., 111, D22308, doi:10.1029/2006JD007327, 2006.

Forster, P. M. and Shine, K. P.: Stratospheric water vapour changes as a possible contributor to observed stratospheric cooling, Geophys. Res. Lett., 26(21), 3309-3312, 1999.

Fueglistaler, S., Wernli, H., and Peter, T.: Tropical troposphereto-stratosphere transport inferred from trajectory calculations, J. Geophys. Res., 109, D03108, doi:10.1029/2003JD004069, 2004.

Fueglistaler, S., Bonazzola, M., Haynes, P., and Peter, T.: Stratospheric water vapour predicted from the Lagrangian temperature history of air entering the stratosphere in the tropics, J. Geophys. Res., 110, D08107, doi:10.1029/2004JD005516, 2005.

Fueglistaler, S. and Haynes, P. H.: Control of interannual and longer-term variability of stratospheric water vapour, J. Geophys. Res., 110 (D24), D24108, doi:10.1029/2005JD006019, 2005.

Gettelman, A., Randel, W. J., Massie, S., and Wu, F.: El Niño as a natural experiment for studying the tropical tropopause region, J. Climate, 14, 3375-3392, 2001.

Gettelman, A., Randel, W. J., Wu, F., and Massie, S. T.: Transport of water vapour in the tropical tropopause layer, Geophys. Res. Lett., 29(1), 1009, doi:10.1029/2001GL013818, 2002.

Gettelman, A., Forster, P. M. de F., Fujiwara, M., Fu, Q., Vömel, H., Gohar, L. K., Johanson, C., and Ammerman, M.: Radiation balance of the tropical tropopause layer, Geophys. Res. Lett., 109, D07103, doi:10.1029/2003JD004190, 2004.

Hatsushika, H. and Yamazaki, K.: Stratospheric drain over Indonesia and dehydration within the tropical tropopause layer diagnosed by air parcel trajectories, J. Geophys. Res., 108(D19), 4610, doi:10.1029/2002JD002986, 2003.

Highwood, E. J. and Hoskins, B. J.: The tropical tropopause, Q. J. Roy. Meteor. Soc., 124, 1579-1604, 1998.

Holton, J. R., Haynes, P. H., McIntyre, M. E., Douglass, A. R., Rood, R. B., and Pfister, L.: Stratosphere-troposphere exchange, Rev. Geophys., 33, 403-440, 1995.

Krüger, K., Tegtmeier, S., and Rex, M.: Long-term climatology of air mass transport through the Tropical Tropopause Layer (TTL) during NH winter, Atmos. Chem. Phys., 8, 813-823, 2008, http://www.atmos-chem-phys.net/8/813/2008/.

Kuo, H. L.: Further studies of the parameterization of the influence of cumulus convection on large scale flow, J. Atmos. Sci., 31, 1232-1240, 1974.

Langematz, U., Grenfell, J., Matthes, K., Mieth, P., Kunze, M., Steil, B., and Brühl, C.: Chemical effects in 11-year solar cycle simulations with the Freie Universität Berlin Climate Middle Atmosphere Model with online chemistry (FUB-CMAM-CHEM), Geophys. Res. Lett., 32, L13803, doi:10.1029/2005GL022686, 2005.

MacKenzie, A. R., Schiller, C., Peter, T., Adriani, A., Beuermann, J., Bujok, O., Cairo, F., Corti, T., DiDonfrancesco, G., Gensch, I., Kiemle, C., Krämer, M., Kröger, C., Merkulov, S., Oulanovsky, A., Ravegnani, F., Rohs, S., Rudakov, V., Salter, P., Santacesaria, V., Stefanutti, L., and Yushkov, V.: Tropopause and hygropause variability over the equatorial Indian Ocean during February and March 1999, J. Geophys. Res., 111, D18112, doi:10.1029/2005JD006639, 2006.

Marti, J. and Mauersberger, K.: A survey and new measurements of ice vapour pressure at temperatures between 170 and $250 \mathrm{~K}$, Geophys. Res. Lett., 20, 363-366, 1993.

Nissen, K. M., Braesicke, P., and Langematz, U.: QBO, SAO, and 
tropical waves in the Berlin TSM GCM: Sensitivity to radiation, vertical resolution, and convection, J. Geophys. Res., 105(D20), 24771-24790, 2000.

Notholt, J., Luo, B., Fueglistaler, S., Weisenstein, D., Rex, M., Lawrence, M.G., Bingemer, H., Wohltmann, I., Corti, T., Warneke, T., von Kuhlmann, R., and Peter, T.: Influence of tropospheric $\mathrm{SO}_{2}$ emissions on particle formation and the stratospheric humidity, Geophys. Res. Lett., 32, L07810, doi:10.1029/2004GL022159, 2005.

Oltmans, S. J. and Hofmann, D. J.: Increase in lower-stratospheric water vapour at a mid-latitude Northern Hemisphere site from 1981 to 1994, Nature, 374, 146-149, 1995.

Parrondo, M. C., Yela, M., von der Gathen, P., and Ochoa, H.: Midwinter lower stratosphere temperatures in the Antarctic vortex: comparison between observations and ECMWF and NCEP operational models, Atmos. Chem. Phys., 7, 435-441, 2007, http://www.atmos-chem-phys.net/7/435/2007/.

Pawson, S., Langematz, U., Radek, G., Schlese, U., and Strauch, P.: The Berlin troposphere-stratospheremesosphere GCM: Sensitivity to physical parametrizations, Q. J. Roy. Meteor. Soc., 124, 1343-1371, 1998.

Ren, C., MacKenzie, A. R., Schiller, C., Shur, G., and Yushkov, V.: Diagnosis of processes controlling water vapour in the tropical tropopause layer by a Lagrangian cirrus model, Atmos. Chem. Phys., 7, 5401-5413, 2007,

http://www.atmos-chem-phys.net/7/5401/2007/.

Schoeberl, M. R, Douglass, A. R., Zhu, Z., and Pawson, S.: A comparison of the lower stratospheric age spectra derived from a general circulation model and two data assimilation systems, J. Geophys. Res., 108(D3), 4113, doi:10.1029/2002JD002652, 2003.
Sherwood, S. C. and Dessler, A. E.: On the control of stratospheric humidity, Geophys. Res. Lett., 27(16), 2513-2516, 2000.

Stenke, A., Dameris, M., Grewe, V., and Garny, H.: Implications of Lagrangian transport for coupled chemistry-climate simulations, Atmos. Chem. Phys. Discuss., 8, 18727-18764, 2008, http://www.atmos-chem-phys-discuss.net/8/18727/2008/.

Tiedtke, M.: A comprehensive mass flux scheme for cumulus parametrization in large-scale models. Mon. Weather Rev., 117, 1779-1800, 1989.

Uppala, S. M., Kallberg, P. W., Simmons, A. J., Andrae, U., Costa Bechtold, V. D. A, Fiorino, M., Gibson, J. K., Haseler, J., Hernandez, A., Kelly, G. A., Li, X., Onogi, K., Saarinen, S., Sokka, N., Allan, R. P., Andersson, E., Arpe, K., Balmaseda, M. A., Beljaars, A. C. M., van de Berg, L., Bidlot, J., Bormann, N., Caires, S., Chevallier, F., Dethof, A., Dragosavac, M., Fisher, M., Fuentes, M., Hagemann, S., Holm, E., Hoskins, B. J., Isaksen, L., Janssen, P. A. E. M., Jenne, R., McNally, A. P., Mahfouf, J.-F., Morcrette, J.-J., Rayner, N. A., Saunders, R. W., Simon, P., Sterl, A., Trenberth, K. E., Untch, A., Vasiljevic, D., Viterbo, P., and Woollen, J.: The ERA-40 re-analysis, Q. J. Roy. Meteor. Soc., 131, 2961-3012, 2005.

Wohltmann, I. and Rex, M.: Improvement of vertical and residual velocities in pressure or hybrid sigma-pressure coordinates in analysis data in the stratosphere, Atmos. Chem. Phys., 8, 265272, 2008, http://www.atmos-chem-phys.net/8/265/2008/.

World Meteorological Organization: Scientific Assessment of Ozone Depletion: 2006, WMO Global Ozone Research and Monitoring Project, Report No. 50, 2007. 